\title{
Resistencia química del hormigón XXIX.-Contribución al estudio del sistema Cemento P-550-ARI hidratado-disolución de sulfato de magnesio
}

DEMETRIO GASPAR-TEBAR, JOSE LUIS SAGRERA-MORENO Y M." FRANCISCA BERMEJO-MUÑOZ
IETCC/CSIC

\section{RESUMEN}

En el presente trabajo, continuación de otros, se estudia el comportamiento de un cemento portland de alta resistencia inicial (P-550-ARI) con unos contenidos calculados (Bogue) de $\mathrm{C}_{3} \mathrm{~S}, \mathrm{C}_{2} \mathrm{~S}, \mathrm{C}_{3} \mathrm{~A}, \mathrm{C}_{4} \mathrm{AF}$ y $\mathrm{CaSO}_{4}$ del 39,2 - 25,7 $9,9-12,0$ y $6,9 \%$, respectivamente, cuando se somete a la acción de una disolución de sulfato de magnesio [2,76 g/l de $\mathrm{MgSO}_{4} .7 \mathrm{H}_{2} \mathrm{O}<>1,12 \times 10^{-2}$ moles/litro de $\mathrm{SO}_{4}$ (II) $<>1,12 \times 10^{-2}$ moles/litro de $\mathrm{Mg}$ (II)], que atraviesa los lechos granulados fabricados con dicho cemento hidratado y curado durante 7 y 28 días, deteminando:

a) la evolución del contenido de los iones $\mathrm{Ca}$ (II), Mg (II) y $\mathrm{SO}_{4}$ (II) de las diversas fracciones recogidas de la disolución de sulfato de magnesio, que han atravesado los lechos de cemento, así como la del pH y de la conductividad,

b) la variación de las cantidades de dichos iones, que se encuentran formando los compuestos correspondientes en el cemento hidratado de los lechos, antes y después de someterlos a la acción de la disolución de sulfato de magnesio,

c) las modificaciones estructurales experimentadas por los compuestos cristalinos del cemento hidratado de los lechos, sometidos a la acción de la disolución mencionada, $y$

d) las características químicas y estructurales de la nueva fase sólida formada en la disolución que ha atravesado los lechos de cemento.

\section{SUMMARY}

In this Work, which is the following of the others, the performance of a portland cement of a high initial resistance (P-550-ARI) - with a calculated content (Bogue) of $39,2-25,7-9,9-12,0$ and $6,9 \%$ of $C_{3} S-C_{2} S-C_{3} A-C_{4} A F$ and $\mathrm{CaSO}_{4}$ (II), respectively - is studied when it is submitted to the action of an magnesium sulfate solution $\left[2,76 \mathrm{~g} / \mathrm{l}\right.$ of $\mathrm{MgSO}_{4} .7 \mathrm{H}_{2} \mathrm{O}<>1,12 \times 10^{-2}$ moles/litre of $\mathrm{SO}_{4}$ (II) $<>1,12 \times 10^{-2}$ moles/litre of $\mathrm{Mg}$ (II)] running across the beds of granulated cement, made with this hydrated cement cured during 7 and 28 days, determining:

a) the evolution of the content on ions $\mathrm{Ca}$ (II), $\mathrm{Mg}$ (II) and $\mathrm{SO}_{4}$ (II) on the taken diverses fractions of magnesium sulfate solution which have run across those beds, so as this of the $\mathrm{pH}$ and the conductivity,

b) the variation in the amount of these ions that are forming the correspondents compounds, in the hydrated cement from the beds that have been submitted before and after to the action of the magnesium sulfate solution,

c) the structural modifications undergone by the crystalline compounds of the hydrated cement from the beds submitted to the action of the magnesium sulfate solution, and

d) the chemical and structural characteristics of the new solid phase formed on the magnesium sulfate solution which have run across the beds of cement.

\section{INTRODUCCION}

En trabajos anteriores (1) (2) se ha estudiado el comportamiento de un cemento portland industrial de alta resistencia inicial (cemento $1<>\mathrm{P}-550-\mathrm{ARI}$ ), análogo al del presente artículo, cuando se somete a la acción del agua desionizada (sistema: cemento P-550-ARI hidratado-agua desionizada) (1) y a la de una disolución de sulfato de sodio (sistema: cemento P-550-ARI hidratado-disolución de sulfato de sodio) (2), que atraviesan sendos lechos granulados fabricados con dicho cemento, una vez hidratado y curado durante 7 y 28 días, determinando la evolución del $\mathrm{pH}$ y de la conductividad, la variación de la concentración de los iones $\mathrm{Ca}$ (II) y $\mathrm{SO}_{4}$ (II) en el agua desioni$\mathrm{da}$, en la disolución de sulfato de sodio y en el cemento de los lechos, así como las modificaciones estructurales experimentadas por los compuestos cristalinos del cemento hidratado de los mencionados lechos.

Por medio del presente trabajo, continuación de otros (3) (4) (5) (6) (7) (8), se pretende contribuir al conocimiento de la resistencia qui- 
mica de los diversos tipos de cemento, en general, frente a la acción de aguas y de disoluciones de sales agresivas $y$, en este caso, de una disolución de sulfato de magnesio cuando fluye a través de un lecho granulado de cemento P-550-ARI hidratado y curado durante 7 y 28 días (sistema: cemento P-550-ARI hidratado-disolución de sulfato de magnesio).

\section{PARTE EXPERIMENTAL}

En este trabajo se estudia el comportamiento de un cemento portland industrial de alta resistencia inicial (P-550-ARI), designado como cemento 1 , cuando los lechos fabricados con dicho cemento 1 - una vez hidratado, granulado y conservado durante 7 y 28 días en un recinto estanco con una humedad relativa superior al $90 \%$, a una temperatura de $21 \pm 2^{\circ} \mathrm{C}-$ se someten a la acción de una disolución de sulfato de magnesio, determinando:

a) La evolución de la concentración de los iones $\mathrm{Ca}$ (II), $\mathrm{Mg}$ (II) y $\mathrm{SO}_{4}$ (II) tanto en las diversas fracciones recogidas de la disolución de sulfato de magnesio, una vez que han atravesado los lechos de cemento hidratado, como en dicho cemento hidratado de! lecho sometido a la acción de la disolución mencionada.

b) La evolución del $\mathrm{pH}$ y de la conductividad de las fracciones extraídas de la disolución de sulfato de magnesio, que han atravesado los lechos de cemento hidratado.

c) Las modificaciones estructurales experimentadas por los compuestos cristalinos del cemento hidratado de los lechos, sometidos a la acción de la disolución de sulfato de magnesio, con relación a la composición estructural del cemento hidratado.

d) Las características químicas y estructurales de la nueva fase sólida formada en la disolución que ha atravesado los lechos de cemento.

\subsection{Materiales utilizados}

\section{a) Cemento 1}

Se ha utilizado el cemento portland industrial de alta resistencia inicial, cemento $1<>$ cemento P-550-ARI, con un contenido calculado (Bogue) del 39,2 \% de $\mathrm{C}_{3} \mathrm{~S}$, del 25,7 \% de $\mathrm{C}_{2} \mathrm{~S}$, del $9,9 \%$ de $\mathrm{C}_{3} \mathrm{~A}$, del $12,0 \%$ de $\mathrm{C}_{4} \mathrm{AF}$ y del $6,9 \%$ de $\mathrm{CaSO}_{4}$, cuyas características químicas, físicas, mecánicas y estructurales se señalan en (3), así como su resistencia química (Koch-Steinegger) frente al agua de mar artificial (3) y a una disolución saturada de yeso (5). b) Disolución de sulfato de magnesio, con una concentración de:

$\mathrm{SO}_{4}(\mathrm{II})=1,076 \mathrm{~g} / \mathrm{I}<>1,12 \times 10^{-2}$ moles/litro y de:

$\mathrm{Mg}$ (II) $=0,272 \mathrm{~g} / \mathrm{l}<>1,12 \times 10^{-2}$ moles/litro

Esta disolución se ha preparado disolviendo 2,76 g $(\times 75)$ de $\mathrm{MgSO}_{4} .7 \mathrm{H}_{2} \mathrm{O}$ en 1 I (X 75) de agua desionizada. La concentración de iones $\mathrm{SO}_{4}$ (II) y $\mathrm{Mg}$ (II), en la disolución, se ha comprobado experimentalmente.

La pureza del $\mathrm{MgSO}_{4} .7 \mathrm{H}_{2} \mathrm{O}$ utilizado se ha determinado por vía química y por DRX.

\subsection{Técnica operatoria}

a) Preparación del lecho

A partir del cemento $1<>$ cemento P-550$A R I$, se han preparado dos lechos granulados de cemento hidratado (uno corresponde a la muestra conservada en la cámara húmeda, con una humedad relativa superior a $90 \%$ y a una temperatura de $21 \pm 2^{\circ} \mathrm{C}$, durante 7 días y otro durante 28 días), según se describe en (1).

\section{b) Equipo y procedimiento operatorio}

Se ha utilizado un equipo de trabajo análogo al descrito en (1) y un procedimiento operatorio similar (1).

\section{c) Preparación de la fase sólida}

La nueva fase sólida formada en las diversas fracciones de la disolución de sulfato de magnesio, que han atravesado los lechos de cemento hidratado, se ha separado de la fase líquida por filtración y se ha secado con una corriente de nitrógeno; a continuación, dada la pequeña cantidad formada (del orden de $\mathrm{mg} /$ fraccción recogida), se ha unido - dicha fase sólida- hasta obtener la cantidad necesaria para poder hacer el estudio correspondiente por DRX y por análisis químico.

\section{b) Determinaciones efectuadas}

En cada una de las distintas fracciones recogidas de la disolución de sulfato de magnesio se ha determinado:

d.1. el contenido de los iones $\mathrm{Ca}$ (II), $\mathrm{Mg}$ (II) y $\mathrm{SO}_{4}$ (II); los dos primeros por complexometría y el tercero gravimétricamente, al estado de $\mathrm{BaSO}_{4}$, 
d.2. el valor del $\mathrm{pH}$ y de la conductividad, utilizando un $\mathrm{pH}$-metro digital, Crison 501, con electrodo Metrohm AG, tipo 9100 Herisau, y un conductímetro digital, Crison 522, con célula Metrohm CH, tipo 9100 Herisau.

En la pasta granulada de cemento hidratado, antes y después de pasar la disolución de sulfato de magnesio, se ha determinado:

d.3. el contenido de los iones $\mathrm{Ca}$ (II), $\mathrm{Mg}$ (II) y $\mathrm{SO}_{4}$ (II), de acuerdo con los procedimientos operatorios descritos en el Pliego $\mathrm{RC}-75(9)$,

d.4. Ia composición estructural por DRX, utilizando el equipo Philips PW-1010 y las condiciones de trabajo que se reseñan en (10).

En la nueva fase sólida se ha determinado, así mismo, el contenido de $\mathrm{Ca}$ (II) y $\mathrm{Mg}$ (II) como en d.1. y la composición estructural como en d.4.

\section{RESULTADOS}

Sistemas: cemento P-550-ARI hidratado (7 y 28 días)-disolución de sulfato de magnesio.

\subsection{Volúmenes extraídos de la disolución de sulfato de magnesio, en función del tiempo}

En la figura 1 se incluyen los volúmenes parciales y totales, recogidos de la disolución de sulfato de magnesio, que han pasado a través de los lechos granulados del cemento 1 hidratado y conservado durante 7 y 28 días.

En el caso del lecho correspondiente al cemento hidratado-conservado durante 7 dias, se ha recogido una extracción por hora $(0,11$ a 0,51 I) en las primeras ocho horas y, a continuación, una en las siguientes quince horas. Posteriormente, se han ido espaciando los tiempos de recogida hasta hacer una extracción cada 24-48 horas. El volumen total recogido ha sido 180,81 litros, durante 39 días.

Para el lecho del cemento hidratado-conservado durante 28 días, la cadencia de recogida ha sido, también, de una extracción por hora $(0,19$ a 1,42 I) durante las ocho primeras horas; posteriormente, se ha realizado una extracción cada 3 horas y, por último, cada 24 horas. A veces, aparecía un precipitado en la disolución que había atravesado el lecho obturando el paso de las llaves del equipo de extracción, lo que obligaba a espaciar el tiempo de recogida y a la limpieza de dichas llaves. El volumen total recogido ha sido 42,94 litros durante 14 días.

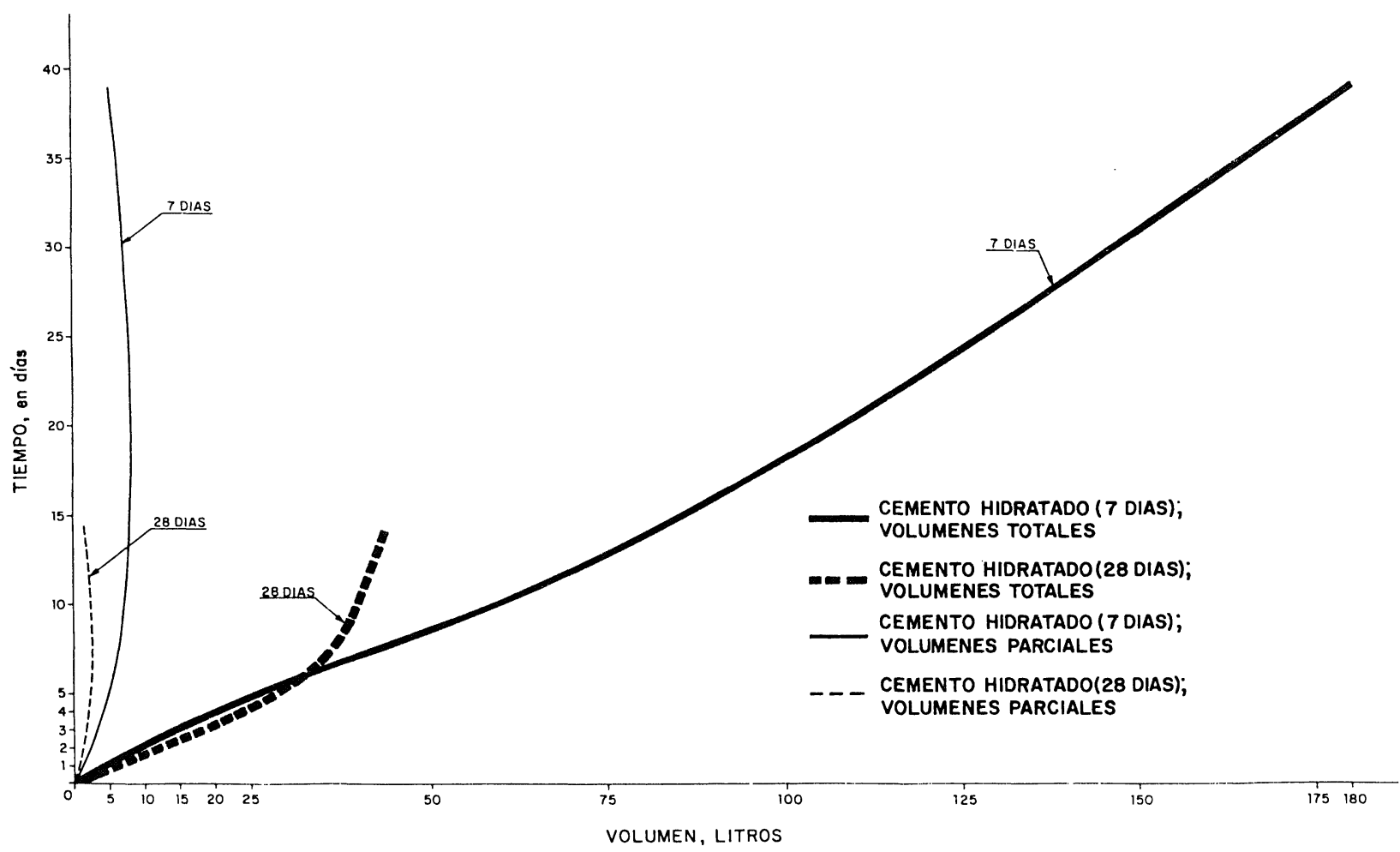

Fig. 1.-Sistemas: cemento 1 hidratado $(7$ y 28 días)-disolución to sulfato de magnesio. Volúmenes parciales y totales en función del tiempo. 


\subsection{Evolución de los contenidos de $\mathrm{Ca}$ (II) y de Mg (II)}

a) Sistema: cemento 1 hidratado (7 días)-disolución de sulfato de magnesio.

Estudio de los valores analíticos.

En la figura 2 se han representado en abscisas las extracciones (volumen acumulado de la disolución, en litros) y en ordenadas las concentraciones de $\mathrm{Ca}$ (II) y de $\mathrm{Mg}$ (II), en (moles/litro) $\times 10^{-2}$, presentes en cada una de las extracciones de la disolución de sulfato de magnesio, que ha atravesado el lecho de cemento hidratado y curado durante 7 días. parcial a partir de esta extracción, disminuyendo la cantidad retenida conforme aumenta el volumen de disolución, hasta que han atravesado el lecho 63,5 litros, en cuyo caso se tienen en la disolución $1,15 \times 10^{-2}$ moles/litro de Mg (II); valor que permanece prácticamente constante en las restantes extracciones.

En este sistema, la evolución del contenido de Mg (II) en la disolución, o retención por el lecho de cemento, está íntimamente ligada a la del Ca (II) en dicha disolución, de tal modo que cuando el contenido de uno aumenta el del otro disminuye y viceversa, excepto cuando la concentración de $\mathrm{Ca}$ (II) es $\geq 1,12 \times 10^{-2}$ moles/litro, en cuyo caso la de $\mathrm{Mg}$ (II) es nula.

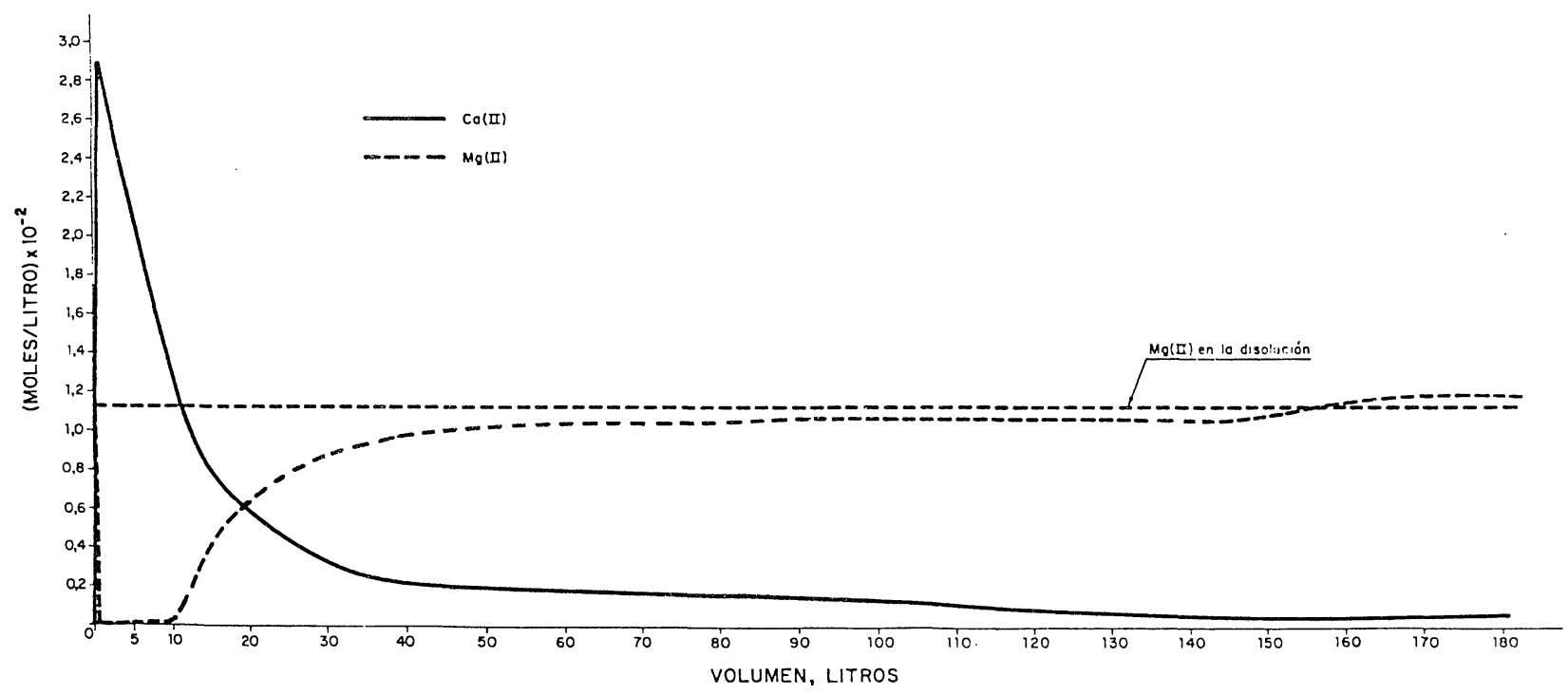

Fig. 2.-Sistema: cemento 1 hidratado (7 días)-disolución de sulfato de magnesio. Evolución de los contenidos de los iones $\mathrm{Ca}$ (II) y $\mathrm{Mg}$ (II).

$\mathrm{El} \mathrm{Ca}(\mathrm{OH})_{2}$, que se encuentra en el cemento hidratado del lecho, se disuelve parcialmente en la disolución de sulfato de magnesio y, en parte, reacciona con el cation $\mathrm{Mg}$ (II) liberando Ca (II) que pasa a la disolución; en las primeras extracciones el contenido de $\mathrm{Ca}$ (II) aumenta, alcanzando su valor máximo $\left(2,9 \times 10^{-2} \mathrm{mo}\right.$ les/litro) cuando han pasado por el lecho 0,86 litros. A continuación, disminuye exponencialmente hasta que se consigue el valor $0,05 \times$ $\times 10^{-2}$ moles/litro (cuando han pasado 113 litros), valor que se mantiene, prácticamente, constante hasta el final del ensayo.

El Mg (II) que se encuentra en la disoiución $\left(1,12 \times 10^{-2}\right.$ moles/litro) disminuye, parcial o totalmente, cuando dicha disolución pasa por el lecho de cemento por ser retenido por el mismo, formando $\mathrm{Mg}(\mathrm{OH})_{2}$. La disminución, o retención por el lecho, es total desde la primera extracción hasta que han pasado 10,9 litros y
Si la concentración de Ca (II) es menor de $0,6 \times 10^{-2}$ moles litro, la de $\mathrm{Mg}$ (II) es mayor de $0,6 \times 10^{-2}$ moles/litro y la suma de ambas es $\simeq 1,12 \times 10^{-2}$ moles/litro; estos valores permanecen, prácticamente, constantes desde que han pasado 63,495 litros de la disolución a través del lecho hasta el final del ensayo.

En las gráficas que representan la evolución de los contenidos de $\mathrm{Ca}$ (II) y de $\mathrm{Mg}$ (II) en las distintas extracciones (figura 2) se puede apreciar que existe un punto de corte, en el que se cumple que la concentración, en moles/litro, de $\mathrm{Ca}$ (II) y la de $\mathrm{Mg}$ (II) son iguales:

$$
[\mathrm{Ca}(\mathrm{II})]=[\mathrm{Mg}(\mathrm{II})]=0,6 \times 10^{-2} \text { moles/litro }
$$

y, además, una zona en donde las concentraciones de $\mathrm{Ca}$ (II) y de $\mathrm{Mg}$ (II) en la disolución permanecen prácticamente constantes, en la 
que se cumple:

$$
\begin{gathered}
{[\mathrm{Ca}(\mathrm{II})]+[\mathrm{Mg}(\mathrm{II})]=\text { cte. }\left(\simeq 1,12 \times 10^{-2}\right.} \\
\text { moles/litro })
\end{gathered}
$$

En general, cuando las concentraciones de cada uno de los iones $\mathrm{Ca}$ (II) y $\mathrm{Mg}$ (II) son menores de $1,12 \times 10^{-2}$ moles/litro, se cumple la expresión anterior.

En la figura 3 se han representado en abscisas las extracciones acumulativas (volumen total de la disolución de sulfato de magnesio que ha pasado por el lecho de cemento hidratado y granulado, en litros) y en ordenadas los moles $\times 10^{-1}$ totales de $\mathrm{Ca}$ (II) extraídos del lecho de cemento y de $\mathrm{Mg}$ (II) presentes en la disolución.
En todas las extracciones ha aparecido un precipitado, a veces en pequeña cantidad, por lo que se ha tenido que unir el de varias extracciones para poder estudiarlo por DRX y por análisis químico.

En el lecho, también, ha aparecido un precipitadado de color blanco de $\mathrm{Mg}(\mathrm{OH})_{2}$, en la zona expuesta directamente a la luz y no en la zona que queda en la sombra.

\section{Balance iónico}

En la tabla 1 figuran los contenidos de $\mathrm{Ca}$ (II) y de $\mathrm{Mg}$ (II) en moles, que existen en los 53,49 $\mathrm{g}$ de cemento puestos inicialmente en el lecho $\mathrm{y}$ en los $36,74 \mathrm{~g}$ de cemento que han quedado, depués de pasar 180,81 litros de la diso-

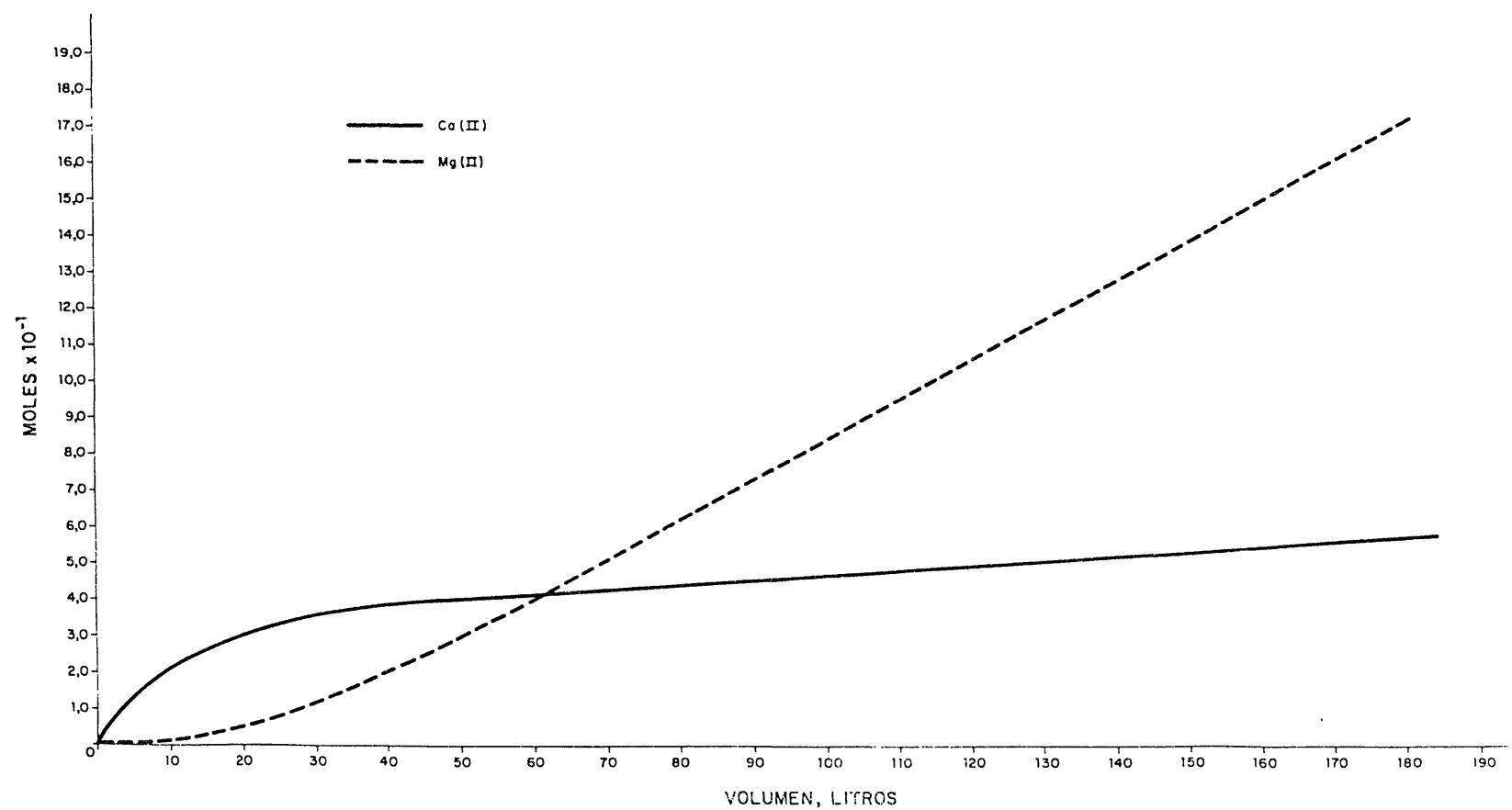

Fig. 3.-Sistema: cemento 1 hidratado (7 días)-disolución de sulfato de magnesio. Evolución de los contenidos de los iones $\mathrm{Ca}($ II) y Mg (II), totales.

En dicha figura se aprecia que en un primer tramo la concentración de Ca (II) aumenta linealmente conforme lo hace el volumen de disolución de sulfato de magnesio (hasta que han pasado 10,9 litros), mientras que la de $\mathrm{Mg}$ (II) es nula. A partir de este volumen, la mencionada extracción de $\mathrm{Ca}$ (II) aumenta ligeramente hasta el final del ensayo, mientras que la cantidad de $\mathrm{Mg}$ (II) en la disolución aumenta linealmente; fenómenos que están de acuerdo con el $\mathrm{Ca}(\mathrm{OH})_{2}$ disuelto, con el $\mathrm{Mg}$ (II) retenido por el lecho, como $\mathrm{Mg}(\mathrm{OH})_{2}$, y con el aporte de iones $\mathrm{Ca}$ (II) del $\mathrm{Ca}(\mathrm{OH})_{2}$. lución de sulfato de magnesio; ambas cantidades de cemento están referidas al producto calcinado. Así mismo, se encuentran los contenidos de dichos iones en la disolución de sulfato de magnesio, antes y después de pasar por el lecho de cemento hidratado y curado durante 7 días.

Los contenidos de $\mathrm{Ca}$ (II) y de $\mathrm{Mg}$ (II) que figuran en la disolución final, corresponden a las cantidades que existen en la fase líquida y en la fase sólida que se ha formado en dicha disolución. 
TABLA 1

Sistema: cemento 1 hidratado (7 días)-disolución de sulfato de magnesio. Cantidades de $\mathrm{Ca}$ (II) y de $\mathrm{Mg}$ (II), en moles, en los componentes iniciales y finales

\begin{tabular}{|c|c|c|c|c|c|c|}
\hline \multirow{2}{*}{ Componentes } & \multicolumn{2}{|c|}{ Cantidades } & \multicolumn{2}{|c|}{$\mathrm{Ca}$ (II), moles } & \multicolumn{2}{|c|}{ Mg (II), moles } \\
\hline & iniciales & finales & iniciales & finales & iniciales & finales \\
\hline Cemento & $53,49 \mathrm{~g}$ & $36,74 \mathrm{~g}$ & 0,57 & 0,03 & $1,92 \times 10^{-2}$ & $20,0 \times 10^{-2}$ \\
\hline Disolución de $\mathrm{MgSO}_{4}$ & 180,811 & $180,81 I$ & 0,00 & 0,56 & 2,02 & 1,76 \\
\hline Suma & & & 0,57 & 0,59 & 2,04 & 1,96 \\
\hline
\end{tabular}

En dicha tabla se puede observar que el $\mathrm{Ca}$ (II) presente en el cemento $(0,57$ moles) ha experimentado una disminución del $94,7 \%$ que se encuentra en la disolución (0,56 moles), mientras que el contenido de $\mathrm{Mg}$ (II) del cemento $\left(1,92 \times 10^{-2}\right.$ moles $)$ se ha incrementado en $18,08 \times 10^{-2}$ moles, habiendo disminuido que la disolución, de tal modo que de los 2,02 moles iniciales han quedado 1,76 moles.

b) Sistema: cemento 1 hidratado (28 días)-disolución de sulfato de magnesio

Estudio de los valores analíticos.

En la figura 4 se han representado en abscisas las extracciones (volumen acumulado de la disolución de sulfato de magnesio en litros) $y$ en ordenadas las concentraciones de $\mathrm{Ca}$ (II) $y$ de $\mathrm{Mg}$ (II), en (moles/litro) $\times 10^{-2}$, que existen en cada una de las extracciones de dicha disolución de sulfato de magnesio, que ha atravesado el lecho de cemento hidratado y curado durante 28 días.

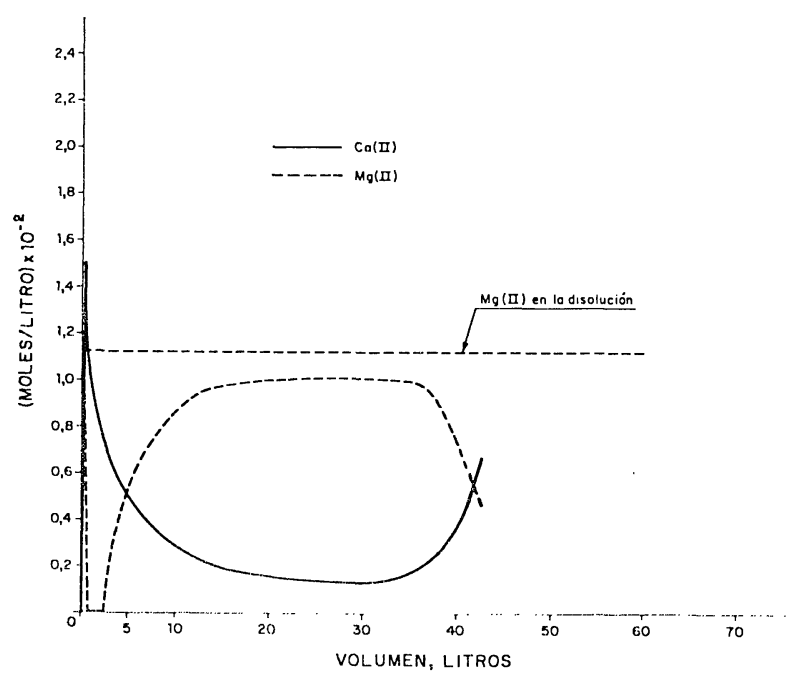

Fig. 4.-Sistema: cemento 1 hidratado (28 días)-disolución de sulfato de magnesio. Evolución de los contenidos de los iones $\mathrm{Ca}$ (II) y $\mathrm{Mg}$ (II).
Como en el caso del lecho de cemento hidratado y curado durante 7 días, el $\mathrm{Ca}(\mathrm{OH})_{2}$ generado en las reacciones de hidratación del cemento y que se encuentra en el lecho se disuelve parcialmente en la disolución de sulfato de magnesio y, en parte, reacciona con el catión Mg (II) liberando Ca (II) que pasa a la disolución; en la segunda extracción el contenido de $\mathrm{Ca}$ (II) en la disolución alcanza el valor máximo $\left(1,5 \times 10^{-2}\right.$ moles/litro) cuando han pasado 0,38 litros de agresivo. A continuación, la cantidad de $\mathrm{Ca}$ (II) disminuye en cada extracción, hasta el valor $0,2 \times 10^{-2}$ moles/litro (cuando han pasado 8,57 litros de la disolución), valor que se conserva prácticamente constante hasta que han pasado 36,53 litros; a partir de este volumen, aumenta dicha cantidad de $\mathrm{Ca}$ (II) alcanzando el valor $0,6 \times 10^{-2}$ moles/litro cuando han atravesado el lecho 41,21 litros de la disolución de sulfato de magnesio.

El Mg (II) presente en la disolución $\left(1,12 \times 10^{-2}\right.$ moles/litro) desaparece de la misma en la primera extracción $(0,19$ litros) y en las siguientes hasta que han pasado 2,34 litros; a partir de esta extracción, dicha cantidad de $\mathrm{Mg}$ (II) en la disolución se incrementa hasta conseguir el valor $1,0 \times 10^{-2}$ moles/litro cuando han pasado por el lecho 12,0 litros del agresivo, valor que permanece prácticamente constante hasta que han pasado por el lecho 38,12 litros, disminuyendo a continuación hasta $0,6 \times 10^{-2}$ moles/litro cuando han atravesado el lecho 41,21 litros de la disolución de sulfato de magnesio (extracción en la que se dió por terminado este estudio).

En este sistema, del mismo modo que en el anterior [cemento hidratado (7 días)-disolución de sulfato de magnesio], la cantidad de $\mathrm{Ca}$ (II) en la disolución se ve influenciada por la presencia de $\mathrm{Mg}$ (II) en dicha disolución y viceversa, de tal modo que cuando la de uno aumenta la del otro disminuye; el $\mathrm{Mg}$ (II) desaparece de la disolución cuando la concentración de Ca (II) es igual o mayor de $1,1 \times 10^{-2}$ moles/litro y permanece prácticamente constante $(\simeq 1,10 \times$ 
$\times 10^{-2}$ moles/litro), así como la de $\mathrm{Ca}$ (II) (menor de $0,2 \times 10^{-2}$ moles/litro), en los casos restantes.

En las gráficas que representan la evolución de los contenidos de $\mathrm{Ca}$ (II) y de $\mathrm{Mg}$ (II) en las distintas extracciones (figura 4) se puede apreciar que existen dos puntos de corte, en los que se cumple:

$$
[\mathrm{Ca} \text { II) }]=[\mathrm{Mg}(\mathrm{II})]=0,6 \times 10^{-2} \text { moles } / \text { litro }
$$

y una zona -en la cual las concentraciones de $\mathrm{Ca}$ (II) y de $\mathrm{Mg}$ (II) permanecen, prácticamente, constantes - en donde la suma de ambas, en moles/litro también es, prácticamente, constante:

$$
\begin{gathered}
{[\mathrm{Ca}(\mathrm{II})]+[\mathrm{Mg}(\mathrm{II})]=\text { cte. }\left(\simeq 1,12 \times 10^{-2}\right.} \\
\text { moles/litro })
\end{gathered}
$$

En la figura 5 se han representado en abscisas las extracciones acumulativas (volumen total de la disolución de sulfato de magnesio que ha atravesado el lecho de cemento, en litros) y en ordenadas los moles $\times 10^{-1}$ totales de $\mathrm{Ca}$ (II) extraídos de dicho lecho de cemento y de Mg (II) presentes en la disolución y que, por consiguiente, no se han eliminado. La evolución del contenido de $\mathrm{Ca}$ (II) en las primeras extracciones es análoga a la del sistema anterior (cemento hidratado y curado durante 7 días); se han extraído $4,11 \times 10^{-2}$ moles/4,90 litros $\langle>0,83$ moles/litro. A partir de este volumen se produce un cambio en la pendiente de la recta, ya que la cantidad de $\mathrm{Ca}$ (II) extraída ha sido $8,57 \times 10^{-2}$ moles/38,04 litros $<>0,22 \times 10^{-2}$ moles/litro. Con relación a la evolución del contenido de $\mathrm{Mg}$ (II) de la disolución de sulfato de magnesio que ha atra. vesado el lecho, se aprecia que en un primer tramo no existe, quedando retenido por el lecho hasta que han pasado 2,5 litros de dicha disolución y que, a partir de este volumen, dicha cantidad de $\mathrm{Mg}$ (II) aumenta linealmente.

En todas las extracciones ha aparecido un

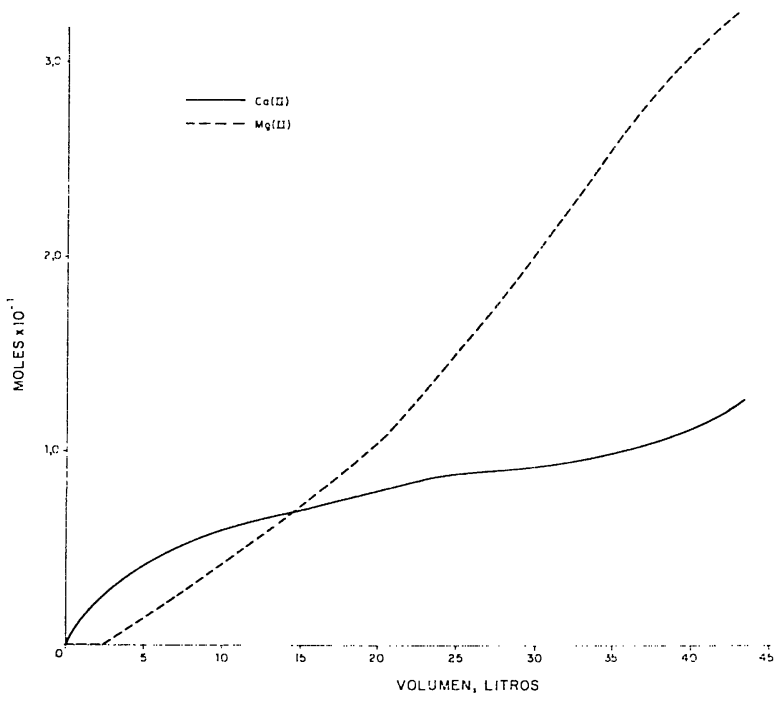

Fig. 5.-Sistema: cemento 1 hidratado (28 días)-disolución de sulfato de magnesio. Evolución de los contenidos de los iones $\mathrm{Ca}$ (II) y Mg (II), totales.

precipitado, a veces en cantidad apreciable y otras del orden de $\mathrm{mg}$, por lo que se ha tenido que unir para tener cantidad suficiente, con objeto de estudiarlo por DRX y por análisis químico.

\section{Balance iónico}

En la tabla 2 figuran los contenidos de $\mathrm{Ca}$ (II) y de $\mathrm{Mg}$ (II), en moles, que existen en los 53,48 g de cemento puestos inicialmente en el lecho y en los $52,38 \mathrm{~g}$ de cemento después de pasar a su través 42,94 litros de la disolución de sulfato de magnesio; ambas cantidades de cemento están referidas al cemento calcinado. Así mismo, se encuentran los contenidos de dichos iones en los 42,94 litros de la disolución de sulfato de magnesio, antes y después de pasar por el lecho de cemento hidratado y curado durante 28 días.

Las cantidades de $\mathrm{Ca}$ (II) y de $\mathrm{Mg}$ (II) que figuran en la disolución final corresponden a las cantidades que existen en la fase líquida y

TABLA 2

\begin{tabular}{|c|c|c|c|c|c|c|}
\hline \multirow{2}{*}{ Componentes } & \multicolumn{2}{|c|}{ Cantidades } & \multicolumn{2}{|c|}{$\mathrm{Ca}$ (II), moles } & \multicolumn{2}{|c|}{ Mg (II), moles } \\
\hline & iniciales & finales & iniciales & finales & iniciales & finales \\
\hline Cemento & $53,48 \mathrm{~g}$ & $52,38 \mathrm{~g}$ & 0,57 & 0,47 & $1,92 \times 10^{-2}$ & $17,3 \times 10^{-2}$ \\
\hline Disolución de $\mathrm{MgSO}_{4}$ & 42,941 & 42,941 & 0,00 & 0,13 & 0,48 & 0,32 \\
\hline Suma & & & 0,57 & 0,60 & 0,50 & 0,49 \\
\hline
\end{tabular}

Sistema: cemento 1 hidratado (28 días)-disolución de sulfato de magnesio Cantidades de $\mathrm{Ca}$ (II) y de $\mathrm{Mg}$ (II), en moles, en los componentes iniciales y finales 
en la nueva fase sólida que se ha formado en dicha disolución.

De los 0,57 moles de Ca (II) que existen en el cemento del lecho original, se han encontrado 0,13 en la disolución; el resto $(0,47$ moles) ha quedado en el cemento del lecho. El Mg (II) presente en la disolución $(0,48$ moles) ha experimentado una disminución de 0,16 moles, que se ha encontrado en el cemento del lecho (0,15 moles); cantidad análoga a la de $\mathrm{Ca}$ (II) que ha pasado a la disolución de sulfato de magnesio.

\subsection{Evolución del contenido de $\mathrm{SO}_{4}$ (II)}

Estudio de los valores analíticos.

En la figura 6 se han representado en abscisas las extracciones (volumen acumulado, en litros) de la disolución de sulfato de magnesio y en ordenadas las concentraciones de $\mathrm{SO}_{4}$ (II), en (moles/litro) $\times 10^{-3}$, presentes en cada una de las extracciones efectuadas en los lechos de cemento 1 hidratado, granulado y curado durante 7 y 28 días.

En el caso del sistema cemento 1 hidratado (7 días)-disolución de sulfato de magnesio se observa que la concentración de $\mathrm{SO}_{4}$ (II) de la disolución $\left(1,12 \times 10^{-2}\right.$ moles/litro) ha experimentado un descenso en las primeras extracciones llegando a ser $0,1 \times 10^{-2}$ moles/litro cuando han pasado 0,29 litros de la disolución (2. ${ }^{a}$ extracción); en las siguientes extracciones el contenido de $\mathrm{SO}_{4}$ (II) en la disolución va aumentando hasta alcanzar el valor $1,08 \times 10^{-2}$ moles/litro cuando han atravesado el lecho 7,25 litros y del mismo orden que el valor inicial de la disolución cuando han pasado 9,90 litros; valor que se conserva hasta el final del ensayo.

La concentración de iones $\mathrm{SO}_{4}$ (II) en la disolución de sulfato de magnesio del sistema cemento 1. hidratado (28 días)-disolución de sulfato de magnesio sigue una evolución análoga a la del caso anterior; las retenciones en las primeras extracciones se encuentran comprendidas entre $0,78 \times 10^{-2}$ a $0,86 \times 10^{-2}$ moles/litro, hasta que han pasado por el lecho 1,42 litros de la disolución de sulfato de magnesio. A partir de este volumen, la retención disminuye (el contenido es mayor) conforme aumenta el volumen hasta que se tiene la concentración $1,09 \times 10^{-2}$ moles/litro cuando han atravesado el lecho 9,63 litros de la disolución; valor que, prácticamente, se conserva hasta el final del ensayo.

En la figura 7 se encuentran representados en abscisas las extracciones acumulativas (volumen total de la disolución de sulfato de magnesio que ha pasado por los lechos, en litros) $y$ en ordenadas los moles $\times 10^{-1}$ totales que existen de $\mathrm{SO}_{4}$ (II), en donde puede apreciarse que las cantidades de $\mathrm{SO}_{4}$ (II) para los dos sistemas [cemento 1 hidratado ( 7 días y 28 días)-disolución de sulfato de magnesio] crece linealmente conforme lo hace el volumen de la disolución. La evolución del contenido de $\mathrm{SO}_{4}$ (II) es análoga en dichos sistemas y dicho contenido es del mismo orden que el de la disolución original.

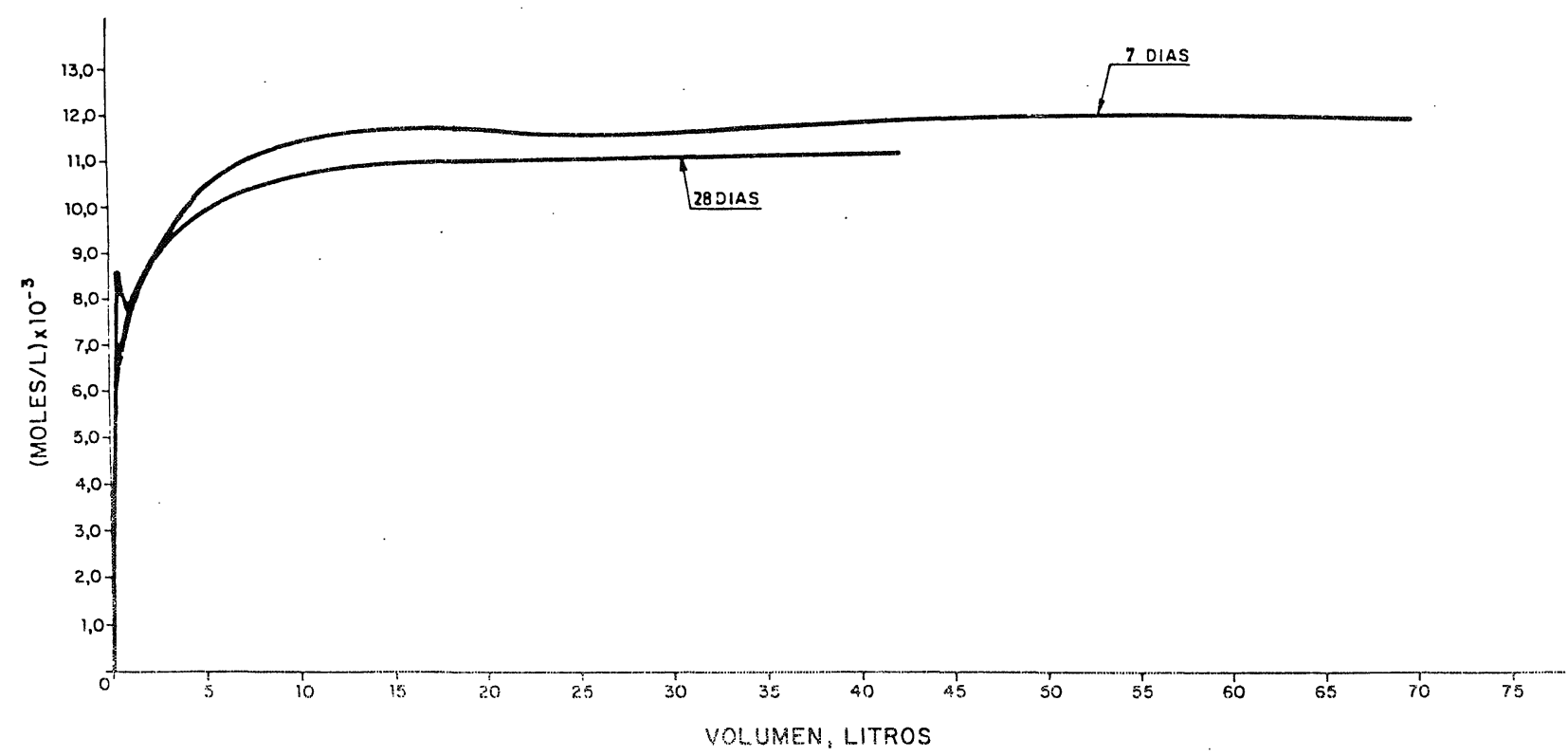

Fig. 6.-Sistemas: cemento 1 hidratado (7 y 28 dias)-disolución de sulfato de magnesio. Evolución del contenido de iones $\mathrm{SO}_{4}(11)$. 


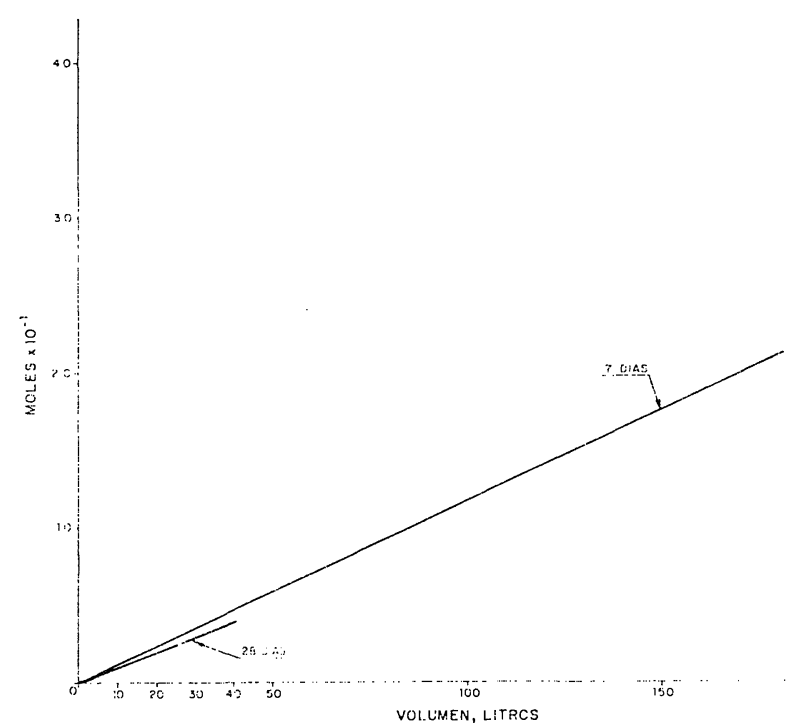

Fig. 7.- Sistemas: cemento 1 hidratado (7 y 28 dias)-disolución de sulfato de magnesio. Evolución del contenido de iones $\mathrm{SO}_{4}$ (II), totales.

\section{Balance iónico}

En la tabla 3 figuran los contenidos de $\mathrm{SO}_{4}$ (II), en moles, que existen en los $53,49 \mathrm{~g}$ y $36,74 \mathrm{~g}$ de cemento, referidos al producto calcinado, puestos inicialmente en el lecho y presentes una vez que han pasado 180,81 litros de la disolución de sulfato de magnesio; así mismo, se encuentran los contenidos de dicho ion en los 180,81 litros de la mencionada disolución antes y después de pasar por el lecho del sistema cemento 1 hidratado ( 7 días)-disolución de sulfato de magnesio.

En la tabla 4 se incluyen los contenidos de $\mathrm{SO}_{4}$ (II) tanto en los $53,48 \mathrm{~g}$ y $52,38 \mathrm{~g}$ de cemento del lecho, referidos al producto calcinado, antes y después de pasar a su través 42,94 litros de la disolución de sulfato de magnesio; asi mismo, se incluyen los contenidos del ion mencionado en dicha disolución antes y después de atravesar el lecho del sistema cemento 1 hidratado (28 días)-disolución de sulfato de magnesio.

En las tablas mencionadas se puede observar que mientras que en el primer sistema (tabla 3) el contenido de ion $\mathrm{SO}_{4}$ (II) del cemento experimenta una disminución de 1,65 $\times 10^{-2}$ moles, para el segundo sistema (tabla 4) dicho contenido se incrementa en $3,35 \times 10^{-2}$ moles. Estas cantidades se corresponden, en gran parte, con el aumento y la disminución experimentadas, respectivamente, en la disolución de sulfato de magnesio.

TABLA 3

Sistema: cemento 1 hidratado (7 días)-disolución de sulfato de magnesio.

Cantidades de $\mathrm{SO}_{4}(\mathrm{II})$, en moles, en los componentes iniciales y finales

\begin{tabular}{|c|c|c|c|c|}
\hline \multirow{2}{*}{ Componentes } & \multicolumn{2}{|c|}{ Cantidades } & \multicolumn{2}{|c|}{$\mathrm{SO}_{4}$ (II), moles } \\
\hline & iniciales & finales & iniciales & finales \\
\hline Cemento & $53,49 \mathrm{~g}$ & $36,74 \mathrm{~g}$ & $2,65 \times 10^{-2}$ & $1,0 \times 10^{-2}$ \\
\hline Disolución de $\mathrm{MgSO}_{4}$ & $180,81 !$ & 180,811 & 2,02 & 2,07 \\
\hline Suma & & & 2,05 & 2,08 \\
\hline
\end{tabular}

TABLA 4

Sistema: cemento 1 hidratado (28 dias)-disolución de sulfato de magnesio.

Cantidades de $\mathrm{SO}_{4}(\mathrm{II})$, en moles, en los componentes iniciales y finales

\begin{tabular}{|l|c|c|c|}
\hline \multicolumn{1}{|c|}{ Componentes } & \multicolumn{2}{c|}{ Cantidades } & \multicolumn{2}{c|}{ So (II), moles } \\
\cline { 2 - 5 } & iniciales & finales & iniciales \\
\hline Cemento & $53,48 \mathrm{~g}$ & $52,38 \mathrm{~g}$ & $2,65 \times 10^{-2}$ \\
Disolución de $\mathrm{MgSO}_{4}$ & 42,941 & $42,94 \mathrm{I}$ & 0,48 \\
\hline Suma & & 0,46 & 0,51 \\
\hline
\end{tabular}




\subsection{Evolución del pH y de la conductividad}

En la figura 8 se han representado los valores del $\mathrm{pH}$ y de la conductividad $(\mathrm{mho} / \mathrm{cm}) \times 10^{-3}$, en ordenadas, de la disolución de sulfato de magnesio que ha atravesado los lechos de cemento hidratado y curado durante 7 y 28 dias, en función del volumen de dicha disolución (litros), en abscisas. tema y $8,57 \times 10^{-3} \mathrm{mho} / \mathrm{cm}$ para el segundo. A continuación, dicha conductividad disminuye exponencialmente, obteniéndose los valores $1,5 \times 10^{-3} \mathrm{mho} / \mathrm{cm}$ para los dos sistemas, cuando han pasado 10,87 litros de la disolución para el sistema cemento 1 hidratado $(7$ días)-disolución de sulfato de magnesio y 2,84 litros para el sistema: cemento 1 hidratado $(28$ días)-disolución de sulfato de magnesio; este

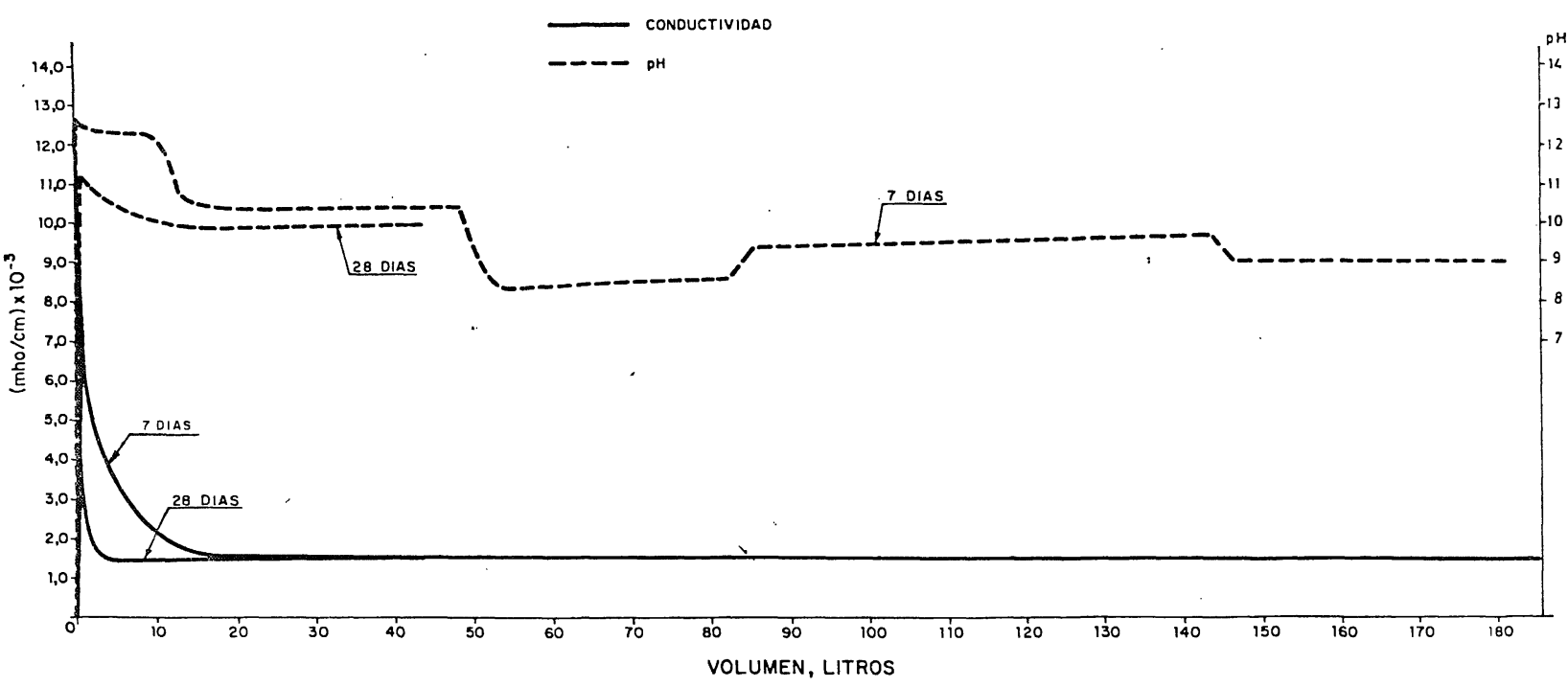

Fig. 8.-Sistemas: cemento 1 hidratado (7 y 28 días)-disolución de sulfato de magnesio. Evolución del pH y de la conductividad.

\section{Evolución del pH}

En el sistema cemento 1 hidratado (7 días)disolución de sulfato de magnesio, el pH presenta valores comprendidos entre 12,9 y 12,2 desde la primera extracción hasta que han pasado por el lecho 10,87 litros de la disolución; a continuación, experimenta un descenso, encontrándose comprendido entre 10,1 y 10,4 y, por último, otro descenso -oscilando entre 7,8 y $10,0-$ hasta el final del ensayo.

En el segundo sistema, el $\mathrm{pH}$ alcanza en la primera extracción el valor máximo $(12,7)$, dis* minuyendo a continuación hasta el valor 10,5, cuando han atravesado el lecho 2,84 litros de la disolución. A partir de este volumen, el pH oscila entre 9,7 y 10,5 hasta el final del ensayo.

\section{Evolución de la conductividad}

En ambos sistemas, la conductividad de la disolución de sulfato de magnesio $\left(1,5 \times 10^{-3}\right.$ $\mathrm{mho} / \mathrm{cm}$ ) experimenta un aumento importante cuando han pasado a través de los lechos de cemento las primeras cantidades de la disolución $(0,17$ - 0,19 litros), alcanzando los valores $12,37 \times 10^{-3} \mathrm{mho} / \mathrm{cm}$ para el primer sis- valor se conserva, prácticamente, constante hasta el final del ensayo en los dos casos estudiados.

\subsection{Estudio por difracción de rayos $X$ del cemento hidratado e hidratado some- tido a la acción de la disolución de sulfato de magnesio}

En la figura 9 se incluyen los DRX del cemento 1 hidratado-curado durante 7 dias $y$ cemento 1 hidratado-curado durante 28 días, antes y después de someterlos a la acción de la disolución de sulfato de magnesio; así mismo, del cemento 1 hidratado y curado durante 7 días, sometido a la acción de dicha disolución, se incluyen los diagramas de la zona superior e inferior del lecho por sus características organolépticas distintas. En dichos difractogramas se han detectado los picos de los siguientes compuestos cristalinos:

a) Diagramas de difracción de rayos $X$ del cemento 1 hidratado (7 y 28 días)

- Ettringita; los picos de este compuesto tienen una intensidad análoga en ambos DRX. 

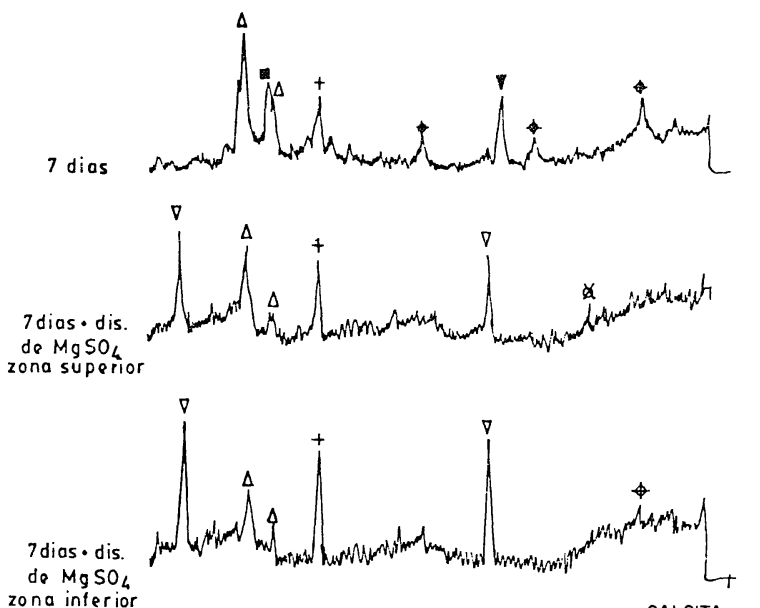

zona inferior + CALCITA

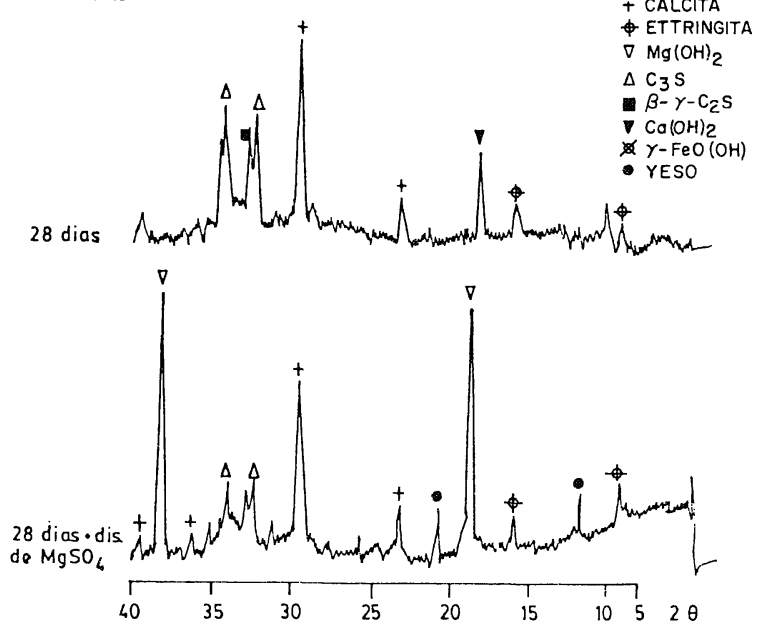

Fig. 9.-Sistemas: cemento 1 hidratado (7 y 28 días)-disolución de sulfato de magnesio. DRX de los cementos hidratados e hidratados-atacados.

- Portlandita; la intensidad de los picos en el DRX del cemento hidratado y curado durante 28 días es 1,25 veces mayor que la del DRX del cemento hidratado y curado 7 días, como consecuencia del avance de las reacciones de hidratación.

- Calcita; la intensidad de los picos en el DRX del cemento hidratado y curado durante 28 días es 3 veces mayor que la del DRX del cemento hidratado y curado 7 días.

- Compuestos anhidros del cemento (fundamentalmente, $\mathrm{C}_{3} \mathrm{~S}$ y $\mathrm{C}_{2} \mathrm{~S}$ ), cuyos picos presentan intensidad análoga en los dos diagramas.

b) Diagramas difracción de rayos $X$ del cemento 1 hidratado-atacado

- Ettringita; los picos de este compuesto se han detectado en los DRX de la muestra correspondiente al lecho fabricado con el cemento hidratado y curado durante 28 días $y$ en el de la parte inferior del fabricado con el cemento hidratado y curado durante 7 días; la intensidad de los picos del DRX correspondiente al cemento hidratado 7 días-atacado es menor que la del diagrama del cemento hidratado 7 días; en el caso del cemento hidratado durante 28 días es a la inversa, es decir, la intensidad de los picos del DRX del cemento hidratado-atacado es mayor.

- Yeso; los picos - de mediana intensidadse han detectado en el DRX correspondiente a la muestra de cemento hidratado y curado durante 28 días después de someterle a la acción del agresivo.

- Brucita; los picos de este compuesto aparecen en los DRX de las tres muestras de cemento sometidas a la acción de la disolución de sulfato de magnesio, presentando mayor intensidad en la muestra de cemento hidratado y curado durante 28 días.

- Calcita; la intensidad de los picos en el diagrama de la muestra hidratada ( 7 días) es menor que la del diagrama del cemento hidratado (28 días) y ésta del mismo orden que la de la muestra del lecho de cemento antes de someterle a la acción de la disolución de sulfato de magnesio.

- Compuestos anhidros del cemento (fundamentalmente, $\mathrm{C}_{3} \mathrm{~S}$ y $\mathrm{C}_{2} \mathrm{~S}$ ); sus picos son de intensidad inferior que en los DRX del cemento 1 hidratado y curado durante 7 ó 28 días, sin someterlo a la acción de la disolución de sulfato de magnesio, por el avance de las reacciones de hidratación en los sistemas estudiados.

- Los picos de la portladita han desaparecido en los DRX de estas dos muestras de cemento 1 hidratado ( 7 y 28 días), sometido a la acción de la disolución de sulfato de magnesio.

- Aparece el compuesto $\gamma-\mathrm{FeO}(\mathrm{OH})$ en el sistema cemento 1 hidratado ( 7 días)-disolución de sulfato de magnesio.

3.6. Estudio por difracción de rayos $X$ de la fase sólida formada en la disolución de sulfato de magnesio que ha atravesado los lechos de cemento

La nueva fase sólida que se ha formado en cada una de las extracciones en ambos sistemas parciales (del orden de $\mathrm{mg}$ ) se ha filtrado, secado en atmósfera inerte, y dada su cantidad -en cada extracción- se ha recogido en cinco grupos, habiendo realizado el DRX de cada una de ellas. 
En todos los DRX correspondientes a las fases sólidas del primer sistema ( 7 días) se han identificado los picos de los compuestos cristalinos calcita y brucita; en los diagramas de las fases sólidas del segundo sistema (28 días) se han identificado los picos de los compuestos cristalinos calcita y brucita en los tres primeros grupos [extracción primera a la décimo primera, inclusive, (3,54 litros)] y en los DRX restantes se han identificado los picos de los compuestos cristalinos aragonito, brucita y calcita; con muy poca intensidad los de este último.

En la figura 10 se incluyen los diez diagramas efectuados.

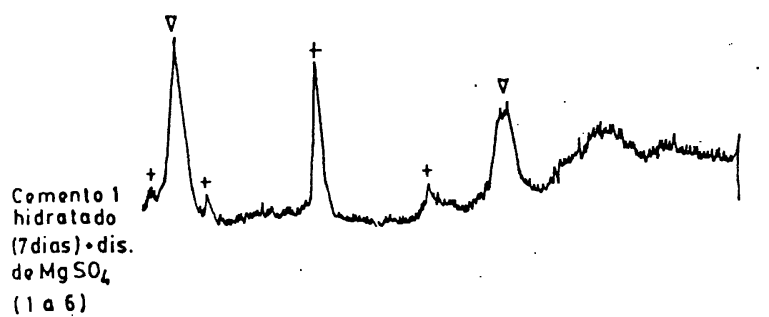
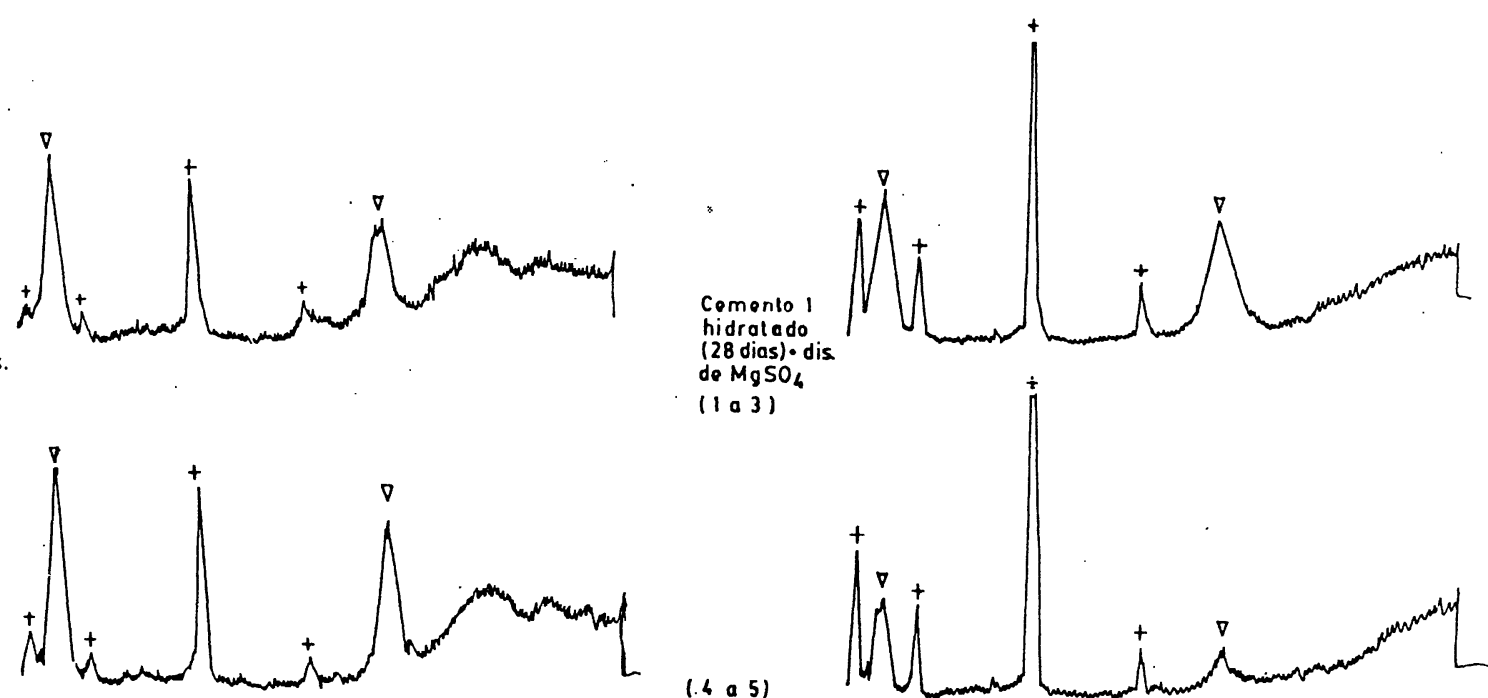

$(7$ y 8$)$ de $\mathrm{MgSO}_{4}$ $\left(\begin{array}{lll}1 & 0 & 3\end{array}\right)$
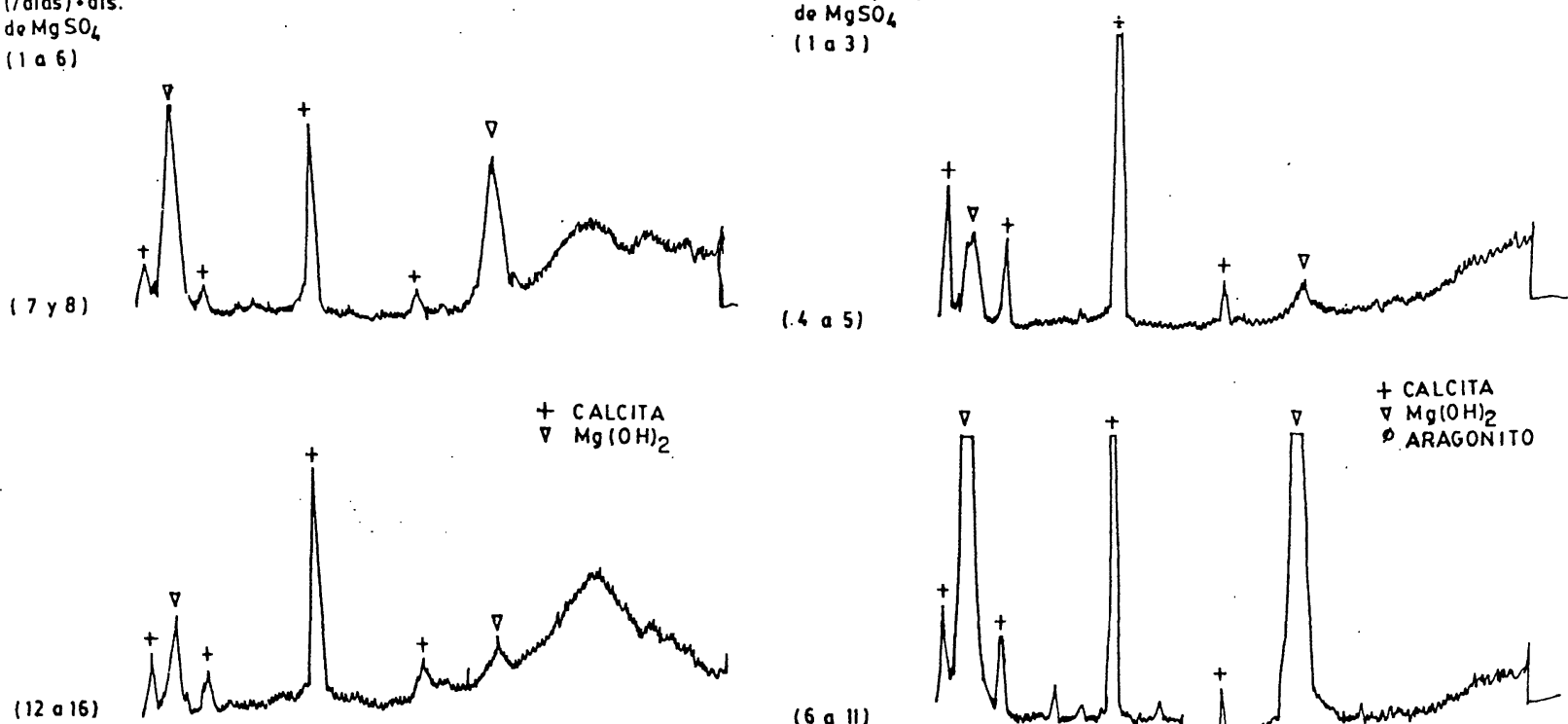

(.4 a 5$)$
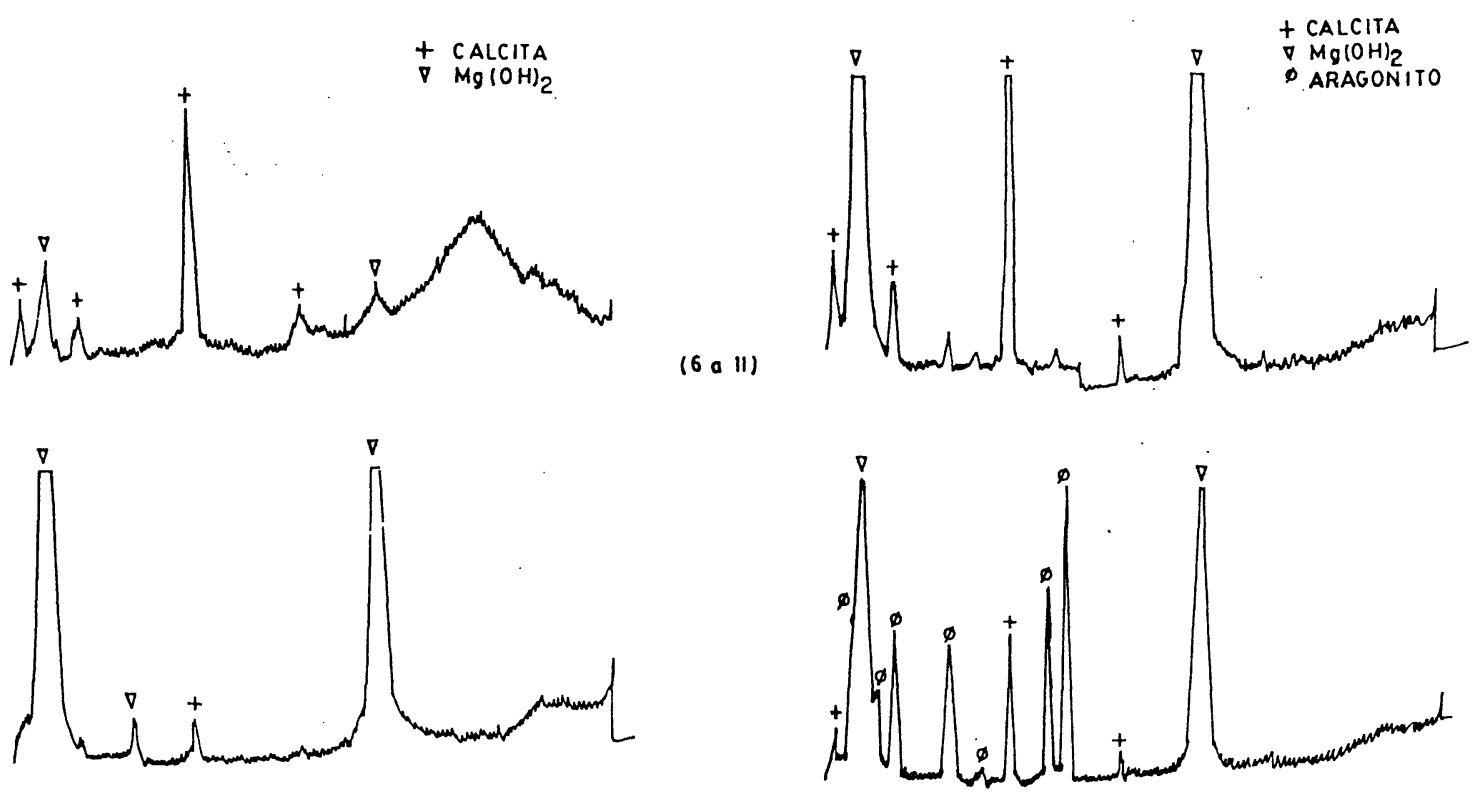

(17)

$(12$ a 17$)$

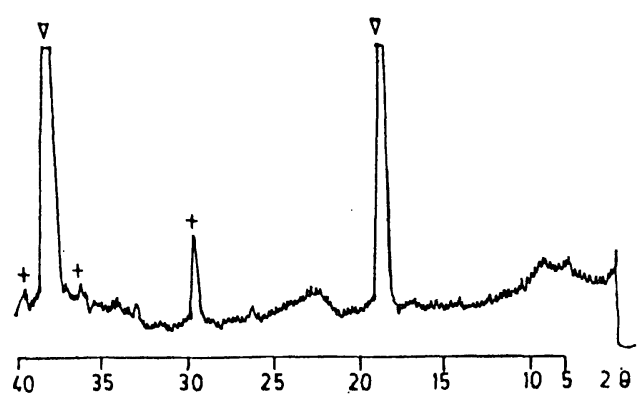

(18 a 29)

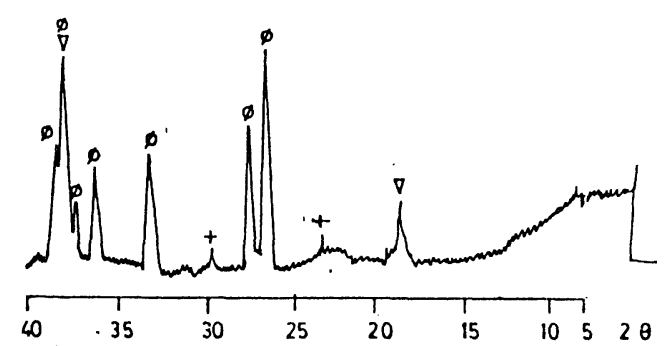

Fig. 10.-Sistemas: cemento 1 hidratado ( 7 y 28 días)-disolución de sulfato de magnesio. DRX de la fase sólida formada en la disolución que ha atravesado los lechos de cemento. 
Para el sistema cemento 1 hidratado (7 días)disolución de sulfato de magnesio se puede observar que entre la extracción primera y la octava (inclusive), coexisten con intensidad análoga los picos de la calcita y de la brucita, de la extracción octava a la décimo primera, inclusive, no aparece precipitado; después, entre la extracción décimo segunda y la décimo sexta, inclusive, la intensidad de los picos de la calcita es mayor que la de los correspondientes a la brucita, y por último, desde la extracción décimo séptima y hasta el final del ensayo, coexisten de nuevo ambos picos, los de la calcita y brucita, si bien, la intensidad de los picos de la brucita es mucho mayor que la de los de la calcita.

Para el cemento 1 hidratado (28 dís)-disolución de sulfato de magnesio se puede observar que a lo largo de todas las extracciones existe precipitado y que la intensidad de los picos de la calcita es mayor que la de los de la brucita en los DRX de la fase sólida correspondiente a las extracciones primera a quinta, mientras que en los diagramas de la sexta a la décimo primera sucede a la inversa.

En los DRX de la fase sólida de las extracciones, décimo segunda a la décimo séptima la intensidad de los picos de la brucita es mayor que la de los del aragonito y a la inversa en los diagramas de la fase sólida formada en las extracciones décimo octava a vigésimo novena. Los picos de la calcita que también aparecen en estos dos últimos DRX presentan una intensidad mucho menor que la de los del aragonito.

\section{INTERPRETACION DE RESULTADOS}

En los sistemas cemento 1 hidratado ( 7 y 28 dias)-disolución de sulfato de magnesio se producen un conjunto de procesos fisicoquímicos que dan lugar a la formación de compues. tos en los lechos de cemento, sometidos a la acción de la mencionada disolución, a la disolución de otros en el agresivo y a la formación de una nueva fase sólida en el seno de la disolución que ha atravesado cualquiera de los dos lechos.

En los lechos de cemento sometidos a la acción de la disolución de sulfato de magnesio, como se ha probado por DRX, se han formado unos compuestos que no existían y han desaparecido otros que se encontraban presentes. Asi, en los DRX del cemento 1 hidratado-curado durante 7 días se han detectado los picos de los compuestos cristalinos brucita y $\gamma$ - FeO(OH), mientras que en los del cemento hidratado-curado durante 28 días se han puesto de manifíesto los correspondientes a la brucita y al yeso; además, en los DRX de ambos cementos (7 y 28 días) han desaparecido los picos de la portlandita y han disminuido los compuestos anhidros de la fracción clinker.

Las diversas fracciones de la disolución que han atravesado los lechos han experimentado modificaciones en lo que se refiere al contenido de $\mathrm{Ca}$ (II), $\mathrm{Mg}$ (II) y $\mathrm{SO}_{4}$ (II), así como del $\mathrm{pH}$ y de la conductividad; por otra parte, se ha formado - en su seno- una nueva fase sólida constituida por los compuestos cristalinos calcita y brucita en el caso del sistema correspondiente al cemento 1 hidratado ( 7 días) $y$, además, por aragonito en determinadas fracciones del sistema cemento 1 hidratado (28 días).

La formación de la brucita, $\mathrm{Mg}(\mathrm{OH})_{2}$, en el cemento hidratado de los lechos, tiene lugar por reacción de los iones $\mathrm{Mg}$ (II) de la disolución con los iones $\mathrm{OH}$ (I) de la portlandita en la interfase del equilibrio $\mathrm{Ca}(\mathrm{OH})_{2}$. sólido $\rightleftharpoons$ $\rightleftharpoons \mathrm{Ca}(\mathrm{OH})_{2}$. disuelto, según $(A)$ :

(A) $\mathrm{Ca}(\mathrm{OH})_{2}$. sólido $\rightleftharpoons \mathrm{Ca}(\mathrm{OH})_{2}$. disuelto $\rightleftharpoons$

$$
\begin{gathered}
\rightleftharpoons \mathrm{Ca}(\mathrm{II})+2 \mathrm{OH}(\mathrm{I}) \\
\mathrm{Mg}(\mathrm{II}) \\
\mathbb{M g}(\mathrm{OH})_{2} . \text { sólido }
\end{gathered}
$$

dando lugar a la formación de $\mathrm{Mg}(\mathrm{OH})_{2}$. sólido ya que:

$$
\left.\begin{array}{l}
P_{s} \mathrm{Mg}(\mathrm{OH})_{2}=1,8 \times 10^{-11} \\
P_{\mathrm{s}}^{\prime} \mathrm{Ca}(\mathrm{OH})_{2}=5,5 \times 10^{-6}
\end{array}\right\} \quad P_{\mathrm{s}}<\mathrm{P}_{\mathrm{s}}
$$

cumpliéndose, por otra parte:

$$
[\mathrm{Mg}(\mathrm{II})] \cdot[\mathrm{OH}(\mathrm{I})]^{2}>\mathrm{P}_{\mathrm{s}}
$$

$y$, por consiguiente, tiene lugar la reacción (B):

$$
\begin{aligned}
& \text { (B) } \underbrace{\mathrm{Ca}(\mathrm{OH})_{2} . \text { sólido }}_{\text {lecho de cemento }}+\frac{\mathrm{Mg}(\mathrm{II})}{\text { disolución }} \rightleftharpoons \\
& \rightleftharpoons \underbrace{\mathrm{Mg}(\mathrm{OH})_{2} \text {. sólido }}_{\text {lecho de cemento }}+\underbrace{\mathrm{Ca}(\mathrm{II})}_{\text {disolución }}
\end{aligned}
$$

en donde se aprecia que por cada mol que desaparece de $\mathrm{Mg}$ (II) en la disolución, aparece otro de Ca (II).

El precipitado de $\mathrm{Mg}(\mathrm{OH})_{2}$ produce en el lecho una disminución de su porosidad, llegando -a veces- - a colmatarlo e impidiendo el paso de la disolución, como se puso de manifiesto en (11). 
El Ca (II) que aparece en la disolución de sulfato de magnesio, que ha atravesado los lechos de cemento 1 hidratado ( 7 y 28 días), procede fundamentalmente de la disolución del $\mathrm{Ca}(\mathrm{OH})_{2}$ formado en las reacciones, según (C):

$$
\begin{aligned}
& \text { (C) } \mathrm{Ca}(\mathrm{OH})_{2} \text {. sólido }\left[\rightleftharpoons \mathrm{Ca}(\mathrm{OH})_{2} \text {. disuelto }\right]+ \\
& + \text { disolución } \rightleftharpoons \underbrace{\mathrm{Ca}(\mathrm{II})+2 \mathrm{OH}(\mathrm{I})}_{\text {disolución }}
\end{aligned}
$$

produciendo un incremento brusco de la basicidad del medio $y$, por consiguiente, del valor del $\mathrm{pH}$.

Además, el Mg (II) de la disolución de sulfato de magnesio, que ha atravesado los lechos de cemento, precipita como $\mathrm{Mg}(\mathrm{OH})_{2}$ al reaccionar con los iones $\mathrm{OH}$ (I) procedentes del $\mathrm{Ca}(\mathrm{OH})_{2}$ disuelto (equilibrio $\mathrm{C}$ ), produciendo una disminución de la basicidad del medio y por consiguiente del $\mathrm{pH}$, según (D):

$$
\text { (D) } \begin{aligned}
& \frac{\mathrm{Mg}(\mathrm{II})}{\text { disolución }}+\underbrace{\mathrm{Ca}(\mathrm{II})+2 \mathrm{OH}(\mathrm{I}) \rightleftharpoons}_{\text {disolución }} \\
\rightleftharpoons & \underbrace{\mathrm{Ca}(\mathrm{II})}_{\text {disolución }}+\underbrace{\mathrm{Mg}(\mathrm{OH})_{2} \text {. sólido }}_{\text {nueva fase sólida }}
\end{aligned}
$$

El $\mathrm{Mg}(\mathrm{OH})_{2}$ es una base bastante débil y precisa un $\mathrm{pH}=10,6$ para que el $\mathrm{Mg}$ (II) de una disolución $10^{-2} \mathrm{M}$ precipite (12); condiciones que se han cumplido en este trabajo. Por otra parte, se ha probado que el Mg (II) de la disolución $\left(1,12 \times 10^{-2}\right.$ moles/litro) ha desaparecido total o parcialmente cuando atraviesa los lechos de cemento 1 ( 7 y 28 días) precipitando totalmente (en los lechos y en las fracciones extraídas de la disolución) cuando la concentración de $\mathrm{Ca}$ (II) en dicha disolución es $\geq 1,12 \times 10^{-2}$ moles/litro y el $\mathrm{pH}>11,5 \mathrm{y}$, parcialmente, cuando la concentración de $\mathrm{Ca}$ (II) es $<1,12 \times 10^{-2}$ moles/litro y el pH $\simeq$ $\simeq 10,5$ (figuras $2,4,8,9$ y 10 ).

Cuando la eliminación del Mg (II) de la disolución, o la precipitación del $\mathrm{Mg}(\mathrm{OH})_{2}$, es parcial se cumple que las concentraciones de los iones $\mathrm{Ca}$ (II) y $\mathrm{Mg}$ (II), en moles/litro, en la disolución es, prácticamente, constante:

$$
\begin{gathered}
{[\mathrm{Ca}(\mathrm{II})]+[\mathrm{Mg}(\mathrm{II})]=\mathrm{cte}\left(\simeq 1,12 \times 10^{-2}\right.} \\
\text { moles/litro })
\end{gathered}
$$

existiendo unos puntos, en la evolución de los contenidos de dichos iones, en donde las concentraciones de ambos son iguales:

$$
[\mathrm{Ca}(\mathrm{II})]=[\mathrm{Mg}(\mathrm{II})]=0,6 \times 10^{-2} \text { moles } / \text { litro }
$$

Estos equilibrios están ligados a las reacciones de hidratación del cemento y a la formación de $\mathrm{Ca}(\mathrm{OH})_{2}$, que se ven favorecidas por la eliminación de iones $\mathrm{OH}(\mathrm{I})$ al precipitar el $\mathrm{Mg}(\mathrm{OH})_{2}$ y por la solubilidad de la portlandita en la disolución; hechos que por otra parte, favorecen el avance de las reacciones de hidratación de la fracción clínker del cemento.

La portlandita que existe en los lechos de cemento experimentan la reacción de carbonatación, fundamentalmente, antes de someterla a la acción de la disolución de sulfato de magnesio, según (E):

(E) $\underbrace{\mathrm{Ca}(\mathrm{OH})_{2} \text {. sólido }\left[\rightleftharpoons \mathrm{Ca}(\mathrm{OH})_{2} \text {.disuelto }\right]}+$ lecho de cemento

$$
+\mathrm{CO}_{2} \rightleftharpoons \underbrace{\mathrm{CaCO}_{3} \text {. sólido }}_{\text {lecho de cemento }}+\mathrm{H}_{2} \mathrm{O}
$$

Así mismo, el $\mathrm{CO}_{2}$ disuelto en la disolución de sulfato de magnesio reacciona, en medio básico fuerte, con los iones $\mathrm{Ca}$ (II) presentes en dicha disolución, que proceden de la disolución de la portlandita, dando lugar a la formación de calcita en el sistema cemento 1 hidratado ( 7 días)-disolución de sulfato de magnesio y de calcita y aragonito en el sistema cemento 1 hidratado (28 días)-disolución de sulfato de magnesio; compuestos cuyos picos se han detectado en los DRX correspondientes a las nuevas fases sólidas que han precipitado en las diversas fracciones recogidas de la disolución (figura 10). La reacción que tiene lugar es la siguiente (equilibrio F):

$$
\begin{gathered}
\underbrace{\mathrm{Ca}(\mathrm{OH})_{2} \text {. sólido }\left[\rightleftharpoons \mathrm{Ca}(\mathrm{OH})_{2} \text {.disuelto }\right]}_{\text {lecho de cemento }}+ \\
+ \text { disolución } \rightleftharpoons \underbrace{}_{\begin{array}{c}
\text { disolución } \\
+ \\
\mathrm{CO}_{2} \\
1 \\
\mathrm{Ca}(\mathrm{II})+2 \mathrm{OH}(\mathrm{I})
\end{array}} \\
\underbrace{\mathrm{CaCO}_{3} \text {.sólido }}_{\text {fase sólida }}+\mathrm{H}_{2} \mathrm{O}
\end{gathered}
$$

produciéndose una disminución de $\mathrm{OH}$ (I) y, por consiguiente, del $\mathrm{pH}$.

La formación de $\mathrm{Mg}(\mathrm{OH})_{2}-\mathrm{pK}=11,5-$, la liberación de $\mathrm{Ca}(\mathrm{OH})_{2}-\mathrm{pK}=5,3-$ por el avance de las reacciones de hidratación, el incremento de $\mathrm{Mg}$ (II) en los lechos de cemento debido, fundamentalmente, a la reacción de precipitación (B) y la regulación del $\mathrm{pH}$, reacción $(\mathrm{E})$, hacen que en determinados casos se favorezca la obtención de $\mathrm{CaSO}_{4}$. $\left..2 \mathrm{H}_{2} \mathrm{O}\right)-\mathrm{pK}=4,6-$ por reacción de los iones 
$\mathrm{SO}_{4}$ (II) de la disolución de sulfato de magnesio con los iones $\mathrm{Ca}$ (II) de la portlandita, según $(\mathrm{G})$ :

(G) $\mathrm{Ca}(\mathrm{OH})_{2}$. solido $\left[\rightleftharpoons \mathrm{Ca}(\mathrm{OH})_{2}\right.$. disuelto $\rightleftharpoons$

$$
\rightleftharpoons \mathrm{Ca}(\mathrm{II})+2 \mathrm{OH}(\mathrm{I})]
$$

lecho de cemento

$+$

$\frac{\text { disolución } \mathrm{MgSO}_{4} \rightarrow \mathrm{Mg}(\mathrm{II})+\mathrm{SO}_{4}(\mathrm{II})}{1} \underbrace{\mathrm{CaSO}_{4} \cdot 2 \mathrm{H}_{2} \mathrm{O} . \text { sólido }+\mathrm{M}}_{1 / \mathrm{Mg}(\mathrm{OH})_{2} \text {. sólido }}$

lecho de cemento

en resumen:

$$
\begin{aligned}
& \frac{\mathrm{Ca}(\mathrm{OH})_{2} \text {. sólido }}{\text { lecho de cemento }}+\frac{\mathrm{Mg}(\mathrm{II})+\mathrm{SO}_{4}(\mathrm{II}) \rightleftharpoons}{\text { disolución } \mathrm{MgSO}_{4}}= \\
& =\underbrace{\mathrm{CaSO}_{4} \cdot 2 \mathrm{H}_{2} \mathrm{O} . \text { sólido }+\mathrm{Mg}(\mathrm{OH})_{2} \text {. sólido }}_{\text {lecho de cemento }}
\end{aligned}
$$

Por otra parte, los iones $\mathrm{SO}_{4}$ (II) de la disolución de sulfato de magnesio con los iones $\mathrm{Ca}$ (II) del $\mathrm{Ca}(\mathrm{OH})_{2}$, presente en los lechos de cemento, y con el aluminato de calcio hidratado del cemento dan lugar a la formación de ettringita en pequeña cantidad (en estos sistemas), según $(H)$ :

(H) $3 \mathrm{Ca}$ (II) $+3 \mathrm{SO}_{4}$ (II) $+3 \mathrm{CaO} \cdot \mathrm{Al}_{2} \mathrm{O}_{3} \cdot 6 \mathrm{H}_{2} \mathrm{O}+$

$$
\begin{aligned}
& 3 \mathrm{CaSO}_{4} \cdot 2 \mathrm{H}_{2} \mathrm{O} \\
+ & 19 \mathrm{H}_{2} \mathrm{O}=3 \mathrm{CaO} \cdot \mathrm{Al}_{2} \mathrm{O}_{3} .3 \mathrm{CaSO}_{4} .31 \mathrm{H}_{2} \mathrm{O}
\end{aligned}
$$

El valor del $\mathrm{pH}$ en la disolución de sulfato de magnesio, que ha atravesado los lechos, viene regido por la presencia de iones $\mathrm{OH}$ (I) procedentes del equilibrio (C) y por la eliminación de parte de los mismos al reaccionar con los iones $\mathrm{Mg}$ (II) y con el $\mathrm{CO}_{2}$, equilibrios (D) y (F), respectivamente.

La conductividad de las fracciones recogidas de la disolución de sulfato de magnesio, que han atravesado los lechos de cemento, es función de los iones presentes y de su concentración, influyendo de un modo especial la correspondiente a los iones $\mathrm{OH}$ (I); ésta llega a ser del mismo orden que la de la disolución de sulfato de magnesio $\left(1,5 \times 10^{-3} \mathrm{mho} / \mathrm{cm}\right)$ en la zona correspondiente a $\mathrm{pH} \simeq 10,5$, y cuando se cumple $[\mathrm{Ca}(\mathrm{II})]+[\mathrm{Mg}(\mathrm{II})]=1,12 \times 10^{-2} \mathrm{moles} / \mathrm{li}-$ tro, es decir cuando la suma de las concentraciones, en moles/litro, de los iones Ca (II) y $\mathrm{Mg}$ (II) es, aproximadamente, igual a la inicial de $\mathrm{Mg}$ (II) de la disolución de sulfato de magnesio.
Las conductividades iónicas equivalentes de los iones estudiados en estos sistemas, a dilución infinita y a $25^{\circ} \mathrm{C}$, expresadas en ohm $^{-1} \cdot \mathrm{cm}^{2}$. equiv. ${ }^{-1}$, son: $\lambda^{\circ}{ }_{\mathrm{Ca} \text { (II) }}=59,5 ; \lambda^{\circ}{ }_{\mathrm{Mg} \text { (II) }}=$ $=53,1 ; \lambda_{\mathrm{OH}(\mathrm{I})}^{\circ}=198,0 ; \lambda_{\mathrm{SO}_{4}(\mathrm{II})}=80,0$ (13).

Las conductividades de estos dos sistemas (la de la disolución de sulfato de magnesio es $\left.1,5 \times 10^{-3} \mathrm{mho} / \mathrm{cm}\right)$ experimentan un incremento importante en las primeras extracciones de la mencionada disolución, alcanzando los valores $12,37 \times 10^{-3} \mathrm{mho} / \mathrm{cm}$ y $8,57 \times 10^{-3}$ $\mathrm{mho} / \mathrm{cm}$ (según el sistema) y posteriormente disminuyen exponencialmente, siguiendo una evolución análoga a la del contenido de $\mathrm{Ca}$ (II) en la disolución de sulfato de magnesio y a la inversa del contenido de $\mathrm{Mg}$ (II) en dicha disolución.

De los fenómenos reseñados, se deduce que la eliminación del $\mathrm{Ca}(\mathrm{OH})_{2}$ del lecho -por formación de $\mathrm{Mg}(\mathrm{OH})_{2}$ y paso a la disolución del ion $\mathrm{Ca}$ (II), y por disolución en el medio que atraviesa los lechos de cemento- favorece las reacciones de hidratación de la fracción clínker del cemento, liberando más portlandita que entra en el proceso anterior, llegando a desaparecer de los lechos, a la vez que los silicatos se degradan.

Las cantidades de $\mathrm{Ca}$ (II) en las primeras extracciones de la disolución de sulfato de magnesio, que ha atravesado el lecho de cemento del sistema correspondiente al cemento 1 hidratado y curado durante 7 días (cuyo valor máximo es $2,9 \times 10^{-2}$ moles/litro), son mayores que las de los sistemas cemento 1 . hidratado (7 días)-agua desionizada y cemento 1 hidratado (7 días)-disolución de sulfato de sodio (los valores máximos son $2,3 \times 10^{-2}$ moles/ /litro y $2,25 \times 10^{-2}$ moles/litro, respectivamente); sin embargo, en el caso del cemento hidratado y curado durante 28 días la cantidad máxima corresponde al agua desionizada $(1,95 \times$ $\left.\times 10^{-2} \mathrm{moles} / \mathrm{litro}\right)$ seguida de la correspondiente a la disolución de sulfato de magnesio $\left(1,5 \times 10^{-2} \mathrm{moles} / \mathrm{litro}\right)$ y de la disolución de sulfato de sodio $\left(1,2 \times 10^{-2}\right.$ moles/litro). Estos hechos ponen de manifiesto la influencia que ejercen determinados iones en la solubilidad de $\mathrm{Ca}(\mathrm{OH})_{2}$, como es el caso del $\mathrm{Mg}$ (II), el cual al formar $\mathrm{Mg}(\mathrm{OH})_{2}$ rompe los equilibrios químicos facilitando el paso a la disolución del catión Ca (II) liberado en la reacción (B), por una parte, y del $\mathrm{Ca}(\mathrm{OH})_{2}$, por otra, como lo prueban los valores de la conductividad.

Los procesos mencionados, que dependen del tiempo de hidratación-curado del cemento 1 , han hecho que las cantidades de cemento de los lechos estudiados experimenten una disminución $[16,75 \mathrm{~g}<>31,3 \%$ en el sistema 1 hidratado (7 días)-disolución de sulfato de magnesio y de $1,1 \mathrm{~g}<>2,0 \%$ en el sistema 
correspondiente al cemento 1 hidratado (28 días)] que se corresponde, fundamentalmente, con las de $\mathrm{Ca}$ (II) y $\mathrm{Mg}$ (II) puestas en juego.

\section{CONCLUSIONES}

\section{Primera}

El cemento estudiado en este trabajo - sometido a la acción de una disolución de sulfato de magnesio que atraviesa los lechos fabricados con él- experimenta modificaciones profundas que afectan, principalmente, a su composición estructural -como se ha puesto de manifiesto por DRX-, dando lugar a la formación de nuevos compuestos cristalinos (yeso, en pequeña cantidad, y brucita), a la eliminación de unos (portlandita) y a la disminución (silicatos anhidros de la fracción clínker) o incremento (calcita y ettringita, en determinados casos y en pequeña magnitud) de otros.

\section{Segunda}

En la mayoria de las fracciones recogidas de la disolución de sulfato de magnesio, que han atravesado los lechos de cemento 1 hidratado y curado durante 7 y 28 días, se ha formado una nueva fase sólida en la que se han detectado -en los diagramas de difracción de rayos $X$ - los picos de los compuestos cristalinos brucita y calcita en todos ellos y, además, los del aragonito en algunos que corresponden al cemento hidratado y curado durante 28 días.

\section{Tercera}

La disolución de sulfato de magnesio, que atraviesa los lechos granulados de cemento hidratado y curado durante 7 y 28 dias, experimenta cambios importantes que afectan, principalmente, al contenido del catión $\mathrm{Mg}$ (II), que en gran parte es retenido por el lecho de cemento en donde precipita como brucita.

\section{Cuarta}

El hidróxido de calcio, presente en el cemento hidratado de los lechos, se disuelve -en su mayoría - en la disolución de sulfato de magnesio que atraviesa dichos lechos y, en parte, reacciona con el catión $\mathrm{Mg}$ (II) de la disolución, quedando libre el catión $\mathrm{Ca}$ (II) que pasa a la disolución mencionada.

Las cantidades del catión Ca (II) presentes en las fracciones recogidas de la disolución de sulfato de magnesio, que pasa por los lechos de cemento, experimenta una disminución exponencial conforme aumenta el volumen de dicha disolución que atraviesa los lechos mencionados.

\section{Quinta}

La evolución del contenido del catión Mg (II) en la disolución, o retención por el lecho, está intimamente ligada a la del $\mathrm{Ca}$ (II), procedente del $\mathrm{Ca}(\mathrm{OH})_{2}$, existiendo una dependencia entre las concentraciones de ambos, de tal modo que cuando la del uno aumenta la del otro disminuye.

Los iones Mg (II) han desaparecido de la disolución que ha atravesado los lechos de cemento, cuando en ésta la concentración de $\mathrm{Ca}$ (II) es $\geq 1,12 \times 10^{-2}$ moles/litro y el $\mathrm{pH}>11,5$, habiendo precipitado como brucita en el cemento del lecho y en la nueva fase sólida. Sin embargo, cuando la concentración de $\mathrm{Ca}$ (II) es $<1,12 \times 10^{-2}$ moles/litro y el $\mathrm{pH}<11$, se elimina parcialmente; en estos casos, se cumple que la suma de las concentraciones de $\mathrm{Ca}$ (II) y de $\mathrm{Mg}$ (II), en moles/litro, es $\simeq 1,12 \times 10^{-2}$.

\section{Sexta}

Los iones $\mathrm{SO}_{4}$ (II) de la disolución de sulfato de magnesio quedan retenidos, parcialmente, en los lechos de cemento, formando yeso y ettringita, en pequeñas cantidades y en determinados casos. Esta retención disminuye a medida que aumenta el volumen de la disolución que atraviesa dichos lechos de cemento; a partir de un volumen dado, la concentración de los iones mencionados permanece, prácticamente constante.

\section{Séptima}

La conductividad de las distintas fracciones recogidas de la disolución de sulfato de magnesio, que han atravesado los lechos de cemento, experimenta un incremento brusco en la primera extracción y, a continuación, una disminución exponencial conforme aumenta el volumen de la disolución de sulfato de magnesio que ha pasado por el lecho. La evolución de la conductividad es función, principalmente, de la concentración de iones $\mathrm{OH}$ (I) presentes en la misma, que - a su vez- es función de la cantidad de $\mathrm{Ca}(\mathrm{OH})_{2}$ disuelto, y que no hayan reaccionado como el $\mathrm{Mg}$ (II) y con el $\mathrm{CO}_{2}$.

Así mismo, el valor del $\mathrm{pH}$ de las mencionadas fracciones recogidas de la disolución de sulfato de magnesio es función de la cantidad de iones $\mathrm{OH}$ (I) presentes en dicha disolución, procedentes - como se ha mencionado- del $\mathrm{Ca}(\mathrm{OH})_{2}$ disuelto, y que no hayan reaccionado con el $\mathrm{Mg}$ (II) y con el $\mathrm{CO}_{2}$. 


\section{Octava}

Los fenómenos reseñados (formación de brucita, calcita, yeso y ettringita en el cemento de los lechos, la eliminación de portlandita, junto con el avance de las reacciones de hidrata- ción) llevan consigo una pérdida de masa en el cemento de los lechos, que depende del tiempo de hidratación-curado del cemento y del volumen de la disolución de sulfato de magnesio que ha pasado por los lechos mencionados.

\section{BIBLIOGRAFIA}

(1) BERMEJO-MUÑOZ, M. F., SAGRERA-MORENO, J. L. y GASPAR-TEBAR, D. (1986): Resistencia química del hormigón. XXVII. Contribución al estudio del sistema: cemento P-550-ARI hidratado-agua desionizada. Materiales de Construcción, 205, 37-47.

(2) BERMEJO-MUÑOZ, $M^{a}$ F SAGRERA-MORENO J. L y GASPAR-TEBAR, D. (1987): Resistencia química del hormigón XXVIII. Contribución al estudio del sistema: cemento P-550-ARI hidratado-disolución de sulfato de sodio. Materiales de Construcción, 206, 61-70.

(3) SAGRERA-MORENO, J. L. y GASPAR-TEBAR, D. (1980): Resistencia química del hormigón. IV. Acción del agua de mar: influencia de la adición de escoria a un cemento portland de alta resistencia inicial. Evolución de las resistencias mecánicas a flexotracción y del coeficiente de corrosión. Materiales de Construcción, 178, 17-38.

(4) GASPAR-TEBAR, D. y SAGRERA-MORENO, J. L. (1981): Resistencia química del hormigón. IX. Influencia de la adición de escoria a un cemento portland de alta resistencia inicial. Estudio por DRX del sistema: cemento 1/escoriaagua potable filtrada. Materiales de Construcción, 181, 33-44.

(5) SAGRERA-MORENO, J. L. y GASPAR-TEBAR, D. (1982): Resistencia química del hormigón. XV. Acción de una disolución saturada de yeso: influencia de la adición de escoria a un cemento portland de alta resistencia inicial. Evolución de las resistencias mecánicas a flexotracción y de los coeficientes de corrosión. Materiales de Construcción, 185, 29-42.

(6) GASPAR-TEBAR, D. y SAGRERA-MORENO, J. L. (1982): Resistencia química del hormigón. XVI. Acción del agua de mar: influencia de la adición de escoria a un cemento portland de alta resistencia inicial. Estudio por DRX. Materiales de Construcción, 186, 39-60.

(7) SAGRERA-MORENO, J. L. y GASPAR-TEBAR, D. (1983): Resistencia química del hormigón. XXI. Influencia de la adición de escoria a un cemento portland de alta resistencia inicial. Estudio de la concentración iónica del sistema: cemento 1/escoria-agua potable filtrada. Materiales de Construcción, 192, 33-41.

(8) GASPAR-TEBAR, D. y SAGRERA-MORENO, J. L. (1984): Resistencia química del hormigón. XXII. Influencia de la adición de escoria a un cemento portland de alta resistencia inicial. Estudio de la concentración iónica del sistema: cemento 1/escoria-agua de mar artificial. Materiales de Construcción, 193, 51-68.

(9) Pliego de Prescripciones Técnicas Generales para la Recepción de Cementos, 1975 (RC-75). MOP, Servicio de Publicaciones, Madrid, 1975.

(10) GASPAR-TEBAR, D., SAGRERA-MORENO, J. L. y BERMEJO-MUÑOZ, M. ${ }^{a}$ F. (1981): Resistencia química del hormigón. XI. Contribución al estudio del sistema: cemento P-450-Y-hidratado-agua desionizada. Materiales de Construcción, $183,17-30$.

(11) GASPAR-TEBAR, D., SAGRERA-MORENO, J. L. y BERMEJO-MUÑOZ, M. ${ }^{a}$ F. (1981): Resistencia química del hormigón. XIV. Contribución al estudio del sistema: cemento P-450-Y hidratado-disolución de sulfato de magnesio. Materiales de Construcción, 184, 65-82.

(12) CHARLOT, G. (1963): L'Analyse Qualitative et les Reactions en Solution. Edit. Masson et Cie. París, págs. 213-216.

(13) CHARLOT, G. (1963): Química Analítica General. Tomo II. Métodos electroquímicos y absorciométricos, cromatografía. Edit. Toray Masson, Barcelona, págs. 123-124.

\section{RECONOCIMIENTO}

Nuestro más sincero agradecimiento a las personas del Equipo de Durabilidad del IETcc: Amalia Rodríguez Pereira, Lucila López Solana, M. ${ }^{a}$ Soledad Cid Fernández, Felipe Cantero Palacios y Manuel Cantero Palacios, así como a M. ${ }^{a}$ Isabel Jiménez, por su valiosa colaboración en la realización de este trabajo. 